\title{
Enriched Expression of Neutral Sphingomyelinase 2 in the Striatum is Essential for Regulation of Lipid Raft Content and Motor Coordination
}

\author{
Laura Hui-Ru Tan ${ }^{1}$ • Angela Jin-Rong Tan ${ }^{1}$ • Yu-Ying $\mathrm{Ng}^{1} \cdot$ John Jia-En Chua ${ }^{2,3,4}$. \\ Wee-Siong Chew ${ }^{5}$ - Sneha Muralidharan ${ }^{6} \cdot$ Federico Torta $^{7} \cdot$ Bamaprasad Dutta $^{8}$. \\ Siu Kwan $\mathrm{Sze}^{8}$ • Deron R. Herr ${ }^{5}$ - Wei-Yi Ong ${ }^{1,2}$ (D)
}

Received: 25 April 2017 / Accepted: 20 September 2017 /Published online: 17 October 2017

(C) The Author(s) 2017. This article is an open access publication

\begin{abstract}
Sphingomyelinases are a family of enzymes that hydrolyze sphingomyelin to generate phosphocholine and ceramide. The brain distribution and function of neutral sphingomyelinase 2 (nSMase2) were elucidated in this study. nSMase 2 mRNA expression was greatest in the striatum, followed by the prefrontal cortex, hippocampus, cerebellum, thalamus, brainstem, and olfactory bulb. The striatum had the highest level of nSMase 2 protein expression, followed by the prefrontal cortex, thalamus, hippocampus, brainstem, and cerebellum. Dense immunolabeling was observed in the striatum, including the caudate-putamen, while moderately dense staining was found in the olfactory bulb and cerebral neocortex. Electron microscopy of the caudate-putamen showed nSMase2 immunoreaction product was present in small diameter dendrites or dendritic spines, that formed asymmetrical synapses with unlabeled axon terminals containing small round vesicles; and characteristics of glutamatergic axons. Lipidomic analysis of the striatum showed increase in long
\end{abstract}

Laura Hui-Ru Tan and Angela Jin-Rong Tan have equal contribution.

Electronic supplementary material The online version of this article (https://doi.org/10.1007/s12035-017-0784-z) contains supplementary material, which is available to authorized users.

Deron R. Herr

phcdrh@nus.edu.sg

Wei-Yi Ong

wei_yi_ong@nuhs.edu.sg

1 Department of Anatomy, National University of Singapore, Singapore 119260, Singapore

2 Neurobiology and Ageing Research Programme, National University of Singapore, Singapore 119260, Singapore

3 Department of Physiology, National University of Singapore, Singapore 119260, Singapore chain sphingomyelins, SM36:1 and SM38:1 after inhibition of nSMase activity. Quantitative proteomic analysis of striatal lipid raft fraction showed many proteins were downregulated by more than 2 -fold after inhibition or antisense knockdown of nSMase; consistent with the notion that nSMase 2 activity is important for aggregation or clustering of proteins in lipid rafts. Inhibition or antisense knockdown of nSMase 2 in the caudate-putamen resulted in motor deficits in the rotarod and narrow beam tests; as well as decreased acoustic startle and improved prepulse inhibition of the startle reflex. Together, results indicate an important function of nSMase 2 in the striatum.

Keywords nSMase 2 - Motor function $\cdot$ Startle reflex . Lipid rafts $\cdot$ GW4869 $\cdot$ Antisense knockdown · Membrane lipids $\cdot$ Microdomains $\cdot$ Lipidomics $\cdot$ Proteomics · Sphingolipids

4 Institute of Molecular and Cell Biology, Agency for Science, Technology and Research (A*STAR), Singapore 138673, Singapore

5 Department of Pharmacology, National University of Singapore, Singapore 119260, Singapore

6 Department of Biological Sciences, National University of Singapore, Singapore 119260, Singapore

7 Department of Biochemistry, National University of Singapore, Singapore 119260, Singapore

8 School of Biological Sciences, Nanyang Technological University, Singapore 637551, Singapore 


\begin{tabular}{|c|c|}
\hline \multicolumn{2}{|c|}{ Abbreviations } \\
\hline$A \beta$ & amyloid beta \\
\hline $\mathrm{AD}$ & Alzheimer's disease \\
\hline AMPA & $\begin{array}{l}\alpha \text {-amino-3-hydroxy-5-methyl-4- } \\
\text { isoxazolepropionic acid }\end{array}$ \\
\hline DAPI & 4',6-diamidino-2-phenylindole \\
\hline LC-MS/MS & $\begin{array}{l}\text { liquid chromatography-mass spectrometry/ } \\
\text { mass spectrometry }\end{array}$ \\
\hline NMDA & $N$-methyl-D-aspartate \\
\hline nSMase2 & neutral sphingomyelinase 2 \\
\hline $\mathrm{PD}$ & Parkinson's disease \\
\hline PMA & phorbol 12-myristate 13 -acetate \\
\hline PVDF & polyvinylidene difluoride \\
\hline $\begin{array}{l}\text { SDS-PAGE } \\
\text { siRNA }\end{array}$ & $\begin{array}{l}\text { sodium dodecyl sulfate polyacrylamide gel } \\
\text { small interfering RNA }\end{array}$ \\
\hline TBS-Tween & Tris-buffered saline-Tween \\
\hline $\mathrm{TNF}-\alpha$ & tumor necrosis factor-alpha \\
\hline TUNEL & $\begin{array}{l}\text { terminal deoxynucleotidyl transferase dUTP } \\
\text { nick end labeling }\end{array}$ \\
\hline
\end{tabular}

\section{Introduction}

Sphingomyelinases (SMases) belong to a class of enzymes that hydrolyze sphingomyelin to generate phosphocholine and ceramide. They play key roles in sphingomyelin breakdown that results in altered neural membrane compositions and the generation of ceramide, a well-established modulator of various important cellular signaling pathways regulating cell differentiation, proliferation, cell survival, and cell death [1-3]. They are categorized according to their $\mathrm{pH}$ level at which their activity is optimal and include lysosomal acid sphingomyelinase (A-SMase), secreted zinc-dependent acid sphingomyelinase (S-SMase), magnesium-dependent neutral sphingomyelinase (nSMase), magnesium-independent neutral sphingomyelinase, and alkaline sphingomyelinase. Of these, A-SMase and nSMase are thought to be the major players in stress-induced ceramide production $[4,5]$. Four neutral nSMases have been identified, namely, nSMase1, nSMase2, nSMase3, and MA-nSMase (mitochondrial-associated $\mathrm{nSMase}$ ). They require a neutral $\mathrm{pH}$ and divalent cations such as $\mathrm{Mg}^{2+}$ or $\mathrm{Mn}^{2+}$ to specifically hydrolyze the phosphocholine-headgroup from sphingomyelin $[6,7]$. With the exception of nSMase3, nSMases possess a DNase I-type catalytic core, suggesting a common mechanism for sphingomyelin catalysis [4].

A comparison of the three nSMase isoforms is presented in Table 1 [8-16]. nSMase2 is a 655 amino acid protein with a molecular weight of $71 \mathrm{kDa}$. It appears to be the most prominent and well-researched isoform. nSMase 2 is localized at the Golgi apparatus and plasma membranes in certain cell lines $[17,18]$. Various factors such as TNF- $\alpha$, PMA [19], and $\mathrm{H}_{2} \mathrm{O}_{2}$ [4] trigger nSMase2 to translocate from the Golgi apparatus to the plasma membrane. nSMase 2 is involved in the modulation of dendritic spine size [20], hippocampal neurite outgrowth, and synaptogenesis [21]. Pharmacological inhibition or genetic mutation of nSMase 2 prevented TNF $\alpha$-induced generation of ceramide, phosphorylation of NR1 subunits, clustering of NR1, enhancement of $N$-methyl-D-aspartate (NMDA)-evoked calcium flux and excitatory post-synaptic currents in cultured hippocampal neurons [22]. nSMase2 inhibition also increased PSD-95, increased the number of AMPA receptors, and impaired spatial and episodic-like memory in mice [23]. Inhibition of nSMase 2 via treatment with nSMase2 siRNA or nSMase inhibitor GW4869 decreases ceramide production and reduces dopamine reuptake in $\mathrm{PC} 12$ cells, while addition of C6 ceramide increases dopamine uptake [24]. nSMase2 may also have a role in Alzheimer's disease. It is activated by $A \beta$ and leads to accumulation of ceramide in neurons, oligodendrocytes and cerebral endothelial cells, and apoptosis [25-27].

Although much attention has been placed on the functional and physiological roles of nSMases in vitro, relatively little is known about the normal expression and function of nSMase 2 in the brain. Previous studies have shown high level of nSMase 2 activity in the parietal cortex and corpus striatum of the rat brain [28]. In this study, we identified the striatum as the brain region that has among the highest expression of nSMase2, and carried out intrastriatal inhibition of nSMase2 to establish its effect on lipid and protein profiles and behavior. Results demonstrate an important role of nSMase 2 in motor function and sensorimotor gating.

\section{Materials and Methods}

\section{Chemicals}

The nSMase inhibitor GW4869 was purchased from Santa Cruz (Santa Cruz Biotechnology, Santa Cruz, USA) and was diluted in vehicle (saline). Antisense and scrambled sense nSMase2 oligonucleotides were purchased from Exiqon (Exiqon A/S, Denmark) of $20 \mathrm{nmol}$ concentration. The sequences were 5' GTAGAAAATCGTGACT $33^{\prime}$ for the antisense and 5' TGATAAAATCGTGGCA $3^{\prime}$ for scrambled sense oligonucleotide. Both antisense and scrambled sense oligonucleotides were reconstituted in $10 \mu \mathrm{l}$ of nuclease-free water.

\section{Animals}

Adult male Wistar rats $(250-300 \mathrm{~g})$ were procured from InVivos Singapore and housed in temperature-controlled $\left(23 \pm 1{ }^{\circ} \mathrm{C}\right)$, individually ventilated cages on a 12-h light/ 12-h dark cycle (7 a.m. -7 p.m.) with access to food and water. 
Table 1 Comparison between the three nSMase isoforms. Based on data from references [8-16]

\begin{tabular}{|c|c|c|c|}
\hline & nSMase1 & nSMase2 & nSMase3 \\
\hline Optimal pH & 7.4 & & \\
\hline Molecular weight (kDa) & 47.5 & 71 & 97.8 \\
\hline Substrate specificity & Lyso-platelet activating factor & Sphingomyelin & \\
\hline \multirow[t]{2}{*}{ Inhibitors } & $\begin{array}{l}\text { 3-O-Methyl-sphingomyelin (3-OMS), } \\
\text { kotylostatin, manumycin A }\end{array}$ & & \\
\hline & No NSM1-specific inhibitor & GW4869, cambinol & Scyphostatin \\
\hline Cellular localization & $\begin{array}{l}\text { Endoplasmic reticulum, Golgi apparatus, } \\
\text { and/or nuclear matrix }\end{array}$ & $\begin{array}{l}\text { Golgi apparatus and plasma } \\
\text { membrane }\end{array}$ & $\begin{array}{l}\text { Endoplasmic reticulum and } \\
\text { Golgi apparatus }\end{array}$ \\
\hline Expression & Multiple tissues & Highest expression in the brain & $\begin{array}{l}\text { Highest expression in striated } \\
\text { muscle and heart muscle }\end{array}$ \\
\hline
\end{tabular}

Rats were acclimatized for 4 days prior to the start of experiments. All procedures were in accordance with the Principles of Laboratory Animal Care and approved by the Institutional Animal Care and Use Committee of the National University of Singapore.

\section{Stereotaxic Injections}

Anesthesia was induced and maintained in rats using the inhalational anesthetic isoflurane (Sigma-Aldrich, St Louis, USA). These were then mounted on a stereotaxic frame (Stoelting, Wood Dale, USA) and the bregma exposed via a midline incision on the scalp. Small craniotomies were performed over the injection sites: $1.0 \mathrm{~mm}$ anterior and $3.0 \mathrm{~mm}$ lateral to the bregma on both sides, and $5.0 \mathrm{~mm}$ from the surface of the cortex. These coordinates correspond to the caudate-putamen of the striatum which was determined using the rat brain atlas of Paxinos and Watson [29]. GW4869 or saline, or antisense or scrambled sense oligonucleotides were injected into the striatum bilaterally. The volume injected at each site was $2 \mu \mathrm{l}$ and the injection rate was 4 min per injection.

Table 2 Acoustic startle reflex. Summary of different trials. The session consisted of 32 discrete trials, which were conducted in pseudorandom order. The prepulse-to-pulse interval was set at $100 \mathrm{~ms}$.

\begin{tabular}{llll}
\hline Trial & $\begin{array}{l}\text { Number } \\
\text { of trials }\end{array}$ & $\begin{array}{l}\text { Intensities } \\
(\mathrm{dB})\end{array}$ & Duration \\
\hline $\begin{array}{l}\text { Acclimation/ } \\
\text { no stimulus }\end{array}$ & - & 65 & $5 \mathrm{~min}$ \\
$\begin{array}{l}\text { Pulse } \\
\text { Prepulse + pulse }\end{array}$ & 5 & 170 & $40 \mathrm{~ms}$ \\
& 5 & $69+120$ & $20 \mathrm{~ms}+40 \mathrm{~ms}$ \\
& 5 & $73+120$ & \\
& & $77+120$ & \\
\hline
\end{tabular}

\section{Real-Time Reverse Transcriptase Polymerase Chain Reaction}

Six adult male Wistar rats were used for this part of the study. They were deeply anesthetized with intraperitoneal injection of ketamine and xylazine cocktail (prepared with $7.5 \mathrm{ml}$ ketamine ( $75 \mathrm{mg} / \mathrm{kg}), 5 \mathrm{ml}$ xylazine $(10 \mathrm{mg} / \mathrm{kg})$, and $7.5 \mathrm{ml} 0.9 \%$ sodium chloride solution) and decapitated. The olfactory bulb, prefrontal cortex, striatum, thalamus, cortex 1 (which includes the primary and secondary motor cortex and primary somatosensory cortex), cortex 2 (which includes the parietal association cortex and secondary auditory cortex), hippocampus, cerebellum, and brainstem were quickly dissected, immersed in RNAlater® solution (Ambion, TX, USA), and snap frozen in liquid nitrogen. TRizol reagent (Invitrogen, CA, USA) was used to extract total RNA, according to the manufacturer's protocol. Purification of RNA was performed using RNeasy® Mini Kit (Qiagen, Inc., CA, USA). Reverse transcription was done using the High-Capacity cDNA Reverse Transcription Kit (Applied Biosystems, CA, USA). The reaction conditions were as follows: $25{ }^{\circ} \mathrm{C}$ for $10 \mathrm{~min}, 37^{\circ} \mathrm{C}$ for $120 \mathrm{~min}$, and $85^{\circ} \mathrm{C}$ for $5 \mathrm{~s}$. Real-time PCR amplification was performed using 7500 Real-Time PCR system (Applied Biosystems, CA, USA), TaqMan® Universal PCR Master Mix (Applied Biosystems, CA, USA), and TaqMan® Gene Expression Assay Probes for A-SMase, nSMase1, nSMase2, nSMase3, and $\beta$-actin (Applied Biosystems, CA, USA) according to the manufacturer's instructions. The PCR conditions were as follows: incubation at $50{ }^{\circ} \mathrm{C}$ for $2 \mathrm{~min}$ and $95{ }^{\circ} \mathrm{C}$ for $10 \mathrm{~min}$ followed by 40 cycles of $95^{\circ} \mathrm{C}$ for $15 \mathrm{~s}$ and $60{ }^{\circ} \mathrm{C}$ for $1 \mathrm{~min}$. All reactions were performed in triplicates. The threshold cycle (CT) was determined based on the number of cycles in which the reporter fluorescence emission exceeded the preset threshold level. Amplified transcripts were calculated using the comparative CT method against the standard curve and the formula for relative fold change $=2^{-\Delta \Delta \mathrm{CT}}[30]$. Relative quantification of each of the nSMase isoforms was performed using a standard curve for each target. 


\section{Western Blot Analysis}

Four adult Wistar rats were used for this part of the study. They were anesthetized deeply and sacrificed by decapitation. Different parts of the rat brain such as the olfactory bulb, prefrontal cortex, striatum, thalamus, cortex 1, cortex 2 , hippocampus, cerebellum, and brain stem were dissected and homogenized using a Tissue Tearor ${ }^{\mathrm{TM}}$ (Biospec, OK, USA) in T-Per® Tissue Protein Extraction Solution containing $1 \%$ Halt $^{\mathrm{TM}}$ protease inhibitor and 1\% EDTA solution (Thermo Fisher Scientific, IL, USA). The homogenates were centrifuged at $12,000 \mathrm{~g}$, and the protein concentration in the supernatant was calculated using the Bio-Rad protein assay kit (Bio-Rad Laboratories, CA, USA). Total proteins were resolved in $15 \%$ SDS polyacrylamide gels under reducing conditions and electrotransferred to polyvinylidene difluoride (PVDF) membranes (Amersham Pharmacia Biotech, Little Chalfont, UK). This was incubated with 5\% skim milk in $0.1 \%$ TBSTween for $1 \mathrm{~h}$ to block non-specific binding sites. The PVDF membrane was then incubated overnight with a rabbit polyclonal antibody to nSMase2, diluted 1:1600 dilution in $5 \%$ skim milk in $0.1 \%$ TBS-Tween at $4{ }^{\circ} \mathrm{C}$. The antibody was raised against a region within amino acids 461 and 655 at the C-terminus of nSMase 2 of human origin (Santa Cruz Biotechnology, Santa Cruz, USA). The membrane was incubated with horseradish peroxidaseconjugated anti-rabbit IgG (ThermoFisher Scientific, MA, USA) for $1 \mathrm{~h}$ at room temperature. Labeled protein was visualized with an enhanced chemiluminescence kit according to the manufacturer's instructions (Pierce, Rockford, IL, USA). Intensities of the bands were quantified using densitometric analyses. Western blots were also used to verify knockdown of nSMase 2 protein by antisense oligonucleotide. Rats used in the rotarod and balance beam tests were anesthetized deeply and sacrificed by decapitation. The striatum was dissected from these rats and analyzed by Western blots to check knockdown efficiency.

\section{Immunohistochemistry}

Six adult Wistar rats were used for this portion of the study. They were anesthetized deeply and perfused through the left cardiac ventricle with a mixture of $4 \%$ paraformaldehyde and $0.1 \%$ glutaraldehyde in $0.1 \mathrm{M}$ phosphate buffer ( $\mathrm{pH} 7.4)$. The brains were removed and sectioned coronally at $100 \mu \mathrm{m}$ using a vibratome. Sections were washed for $3 \mathrm{~h}$ with phosphatebuffered saline (PBS) and incubated overnight at $4{ }^{\circ} \mathrm{C}$ with an affinity-purified rabbit polyclonal antibody to nSMase2 (Santa Cruz Biotechnology, Santa Cruz, USA), diluted 1:200 in PBS. They were then incubated for $1 \mathrm{~h}$ in a 1:200 dilution of biotinylated horse anti-rabbit IgG (Vector, Burlingame, CA, USA), reacted for $1 \mathrm{~h}$ with avidin-biotinylated horseradish peroxidase complex, and treated for $5 \mathrm{~min}$ in $0.05 \% 3,3$ diaminobenzidine tetrahydrochloride solution in Tris buffer containing $0.05 \%$ hydrogen peroxide. Some of the sections were mounted on glass slides, counterstained with methyl green, and coverslipped, while the remaining sections were processed for electron microscopy.

\section{Electron Microscopy}

Immunostained sections of the striatum were subdissected into smaller portions and stained with $1 \%$ osmium tetroxide for $1 \mathrm{~h}$. They were dehydrated in an ascending series of 25,50 , 75 , and $100 \%$ ethanol and acetone, and embedded in Araldite. Thin sections were obtained from the first $5 \mu \mathrm{m}$ of the immunostained sections, mounted on Formvar-coated copper grids, and stained with lead citrate. They were viewed using a JEOL 1010EX electron microscope (JEOL, Japan).

\section{Lipidomic Analysis}

Rats that have completed the rotarod and balance beam tests (see below) were used for this part of the study, with six rats in each group that received GW4869 or saline injection to the caudate-putamen. These were deeply anesthetized and sacrificed by decapitation, and the striatum dissected out and snap frozen in liquid nitrogen. The tissue was thawed, and weighed, and lipids were extracted and analyzed for lipidomics as previously described [31]. Briefly, the tissue was transferred to Omni tubes containing $50 \mathrm{mg}$ of 1.4-mm ceramic beads. One milliliter of BUME (butanol: methanol 1:1) mixture containing $1.07 \mathrm{nmol} / \mathrm{ml}$ of 12:0 SM (860583, Avanti Polar Lipids, USA) and $0.18 \mathrm{nmol} / \mathrm{ml}$ of $\mathrm{C} 17$ ceramide (860517, Avanti Polar Lipids, USA) standards was added to around $30 \mathrm{mg}$ of wet tissue that was then homogenized for few seconds using an Omni bead mill homogenizer. The homogenized tissue was sonicated for $30 \mathrm{~min}$ and centrifuged at $14,000 \mathrm{~g}$ to precipitate the protein phase. The supernatant, containing the extracted lipids, was analyzed by positive mode electrospray ionization (ESI) mass spectrometry (MS) using an Agilent 6495 QQQ mass spectrometer. Lipid separations were performed on a UHPLC Agilent 1290, using a reversed phase Agilent ZORBAX RRHD Eclipse Plus C18 column $(95 \AA, 2.1 \times 100 \mathrm{~mm}, 1.8 \mu \mathrm{m})$ at $40{ }^{\circ} \mathrm{C}$. Mobile phases A ( $40 \%$ acetonitrile in $60 \%$ water with $10 \mathrm{mM}$ ammonium formate) and B (10\% acetonitrile in $90 \%$ isopropanol with $10 \mathrm{mM}$ ammonium formate) were mixed according to the following gradient: $20 \% \mathrm{~B}$ at $0 \mathrm{~min}$, to $60 \% \mathrm{~B}$ at $2.0 \mathrm{~min}$, to $100 \% \mathrm{~B}$ at $7.0 \mathrm{~min}$, maintained at $100 \% \mathrm{~B}$ from 7.0 to $9.0 \mathrm{~min}$, re equilibrated at $20 \% \mathrm{~B}$ from $9.01 \mathrm{~min}$ to $10.80 \mathrm{~min}$. Lipids were measured using a dynamic MRM method. Possible significant differences were analyzed using Student's $t$ test. $P<0.05$ was considered significant. 


\section{Proteomic Analysis of Lipid Rafts}

Rats that have completed the rotarod and balance beam tests were used for this part of the study, with six rats in each group that received GW4869 or saline; or antisense or scrambled sense oligonucleotide injection to the caudate-putamen. To determine if nSMase2 was involved in the proteome of lipid rafts, a label-free quantitative proteomics approach was carried out using LC-MS/MS analysis and Protein Abundance Index (emPAI) protocol. Rats were anesthetized deeply and sacrificed by decapitation. The striatum was dissected out, and in view of the small amount of tissue, lipid rafts were isolated using the UltraRIPA kit according to the manufacturer's instructions (BioDynamics Laboratory, Japan). This is a novel but validated small-scale platform to rapidly extract membrane proteins or membrane-associated proteins enriched in lipid rafts with a native structure and function [32]. In brief, rat striatal samples were first homogenized in conventional RIPA buffer (50 mM Tris- $\mathrm{HCl}(\mathrm{pH} 8.0), 150 \mathrm{mM} \mathrm{NaCl}, 1 \%$ NP-40 alternative, $0.1 \%$ SDS, and $0.5 \%$ sodium deoxycholate) using a Tissue Tearor ${ }^{\mathrm{TM}}$ (Biospec, OK, USA). After purification of the RIPA-insoluble fraction, lipid raft proteins were extracted using another B-buffer which solubilizes the RIPA-insoluble lipid raft proteins (BioDynamics Laboratory, Japan). Lipid raft fractions from the four groups were resolved by $12.5 \%$ SDS-PAGE and stained with Coomassie brilliant blue. Each sample lane was cut separately and sliced into small pieces for destaining, washing, reduction, alkylation, and trypsin digestion using sequencing-grade modified trypsin (Promega, Madison, WI), at $37^{\circ} \mathrm{C}$ overnight. Tryptic peptides were extracted with $5 \%$ acetic acid $/ 50 \%$ ACN buffer and vacuum dried. They were reconstituted in $0.1 \%$ formic acid (FA) solution before LC-MS/MS analysis using an online Dionex UltiMate 3000 UHPLC system coupled with a Q Exactive mass spectrometer (Thermo Scientific Inc., Bremen, Germany). Each sample was injected into the LC-MS/MS for three times. The acquired raw data were converted into the mascot generic format (mgf) files using Proteome Discoverer 1.4.1.14 software (Thermo Fisher, MA) with MS2 spectrum processor for deisotoping. All the searches were performed using the in-house mascot search engine (Mascot, version 2.4.1; Matrix Science, London, UK) using UniProt Knowledgebase (UniProtKB) rat database (31,555 sequences, 17,339,165 residues) along with the reverse sequences. Carbamidomethyl at cysteine was set as a static modification and methionine oxidation, and asparagines and glutamine deamidation as dynamic modifications. Full trypsin digestion with maximum 2 missed and/ or non-specific cleavages set as digestion parameter; while no. $13 \mathrm{C}$ of 2, $10 \mathrm{ppm}$ precursor mass, and 0.02-Da fragment mass tolerance were set as other search parameters. Target-decoy search strategy with cutoff set to $\leq 1 \%$ false density rate (FDR) and proteins identified with $>2$ unique peptides were

used for further analysis. The emPAI value for each identified protein was calculated by Mascot during search and was used for the label-free quantification.

\section{Rotarod Test}

Six adult male Wistar rats in each group, i.e., GW4869, saline, antisense-, or scrambled sense oligonucleotides, were used in this portion of the study. Rats underwent intrastriatal injection of GW4869 or saline $6 \mathrm{~h}$ before undergoing the rotarod test. The latter was carried out 6-h post injection, since the inhibitory effect of GW4869 was shown to be significantly reduced by $24 \mathrm{~h}$ [12]. For the oligonucleotide-injected groups, rats underwent intrastriatal injection of antisense or scrambled sense oligonucleotides before undergoing rotarod testing for 5 days. They were positioned on an accelerating rotarod cylinder and were timed based on how long they remained on the rotarod. The speed gradually increased from 4 to $40 \mathrm{rpm}$ within a span of $5 \mathrm{~min}$. A trial was considered to have ended when a rat fell off the rotarod cylinder or gripped the cylinder and spun for 2 successive revolutions without trying to walk on the rungs. The duration (in seconds) on the device was recorded. Rotarod test data were presented as average latency to fall (3 trials) from the rotarod. Possible significant differences were analyzed using Student's $t$ test. $P<0.05$ was considered significant.

\section{Beam Crossing Test}

The time to cross the center $80 \mathrm{~cm}$ of a 1 - $\mathrm{m}$ round beam of 2.5 $\mathrm{cm}$ diameter was recorded. The beam was elevated $90 \mathrm{~cm}$ over the ground and had to be crossed three times. Rats were

\section{mRNA Expression of Sphingomyelinase Isoforms in the Rat Brain}

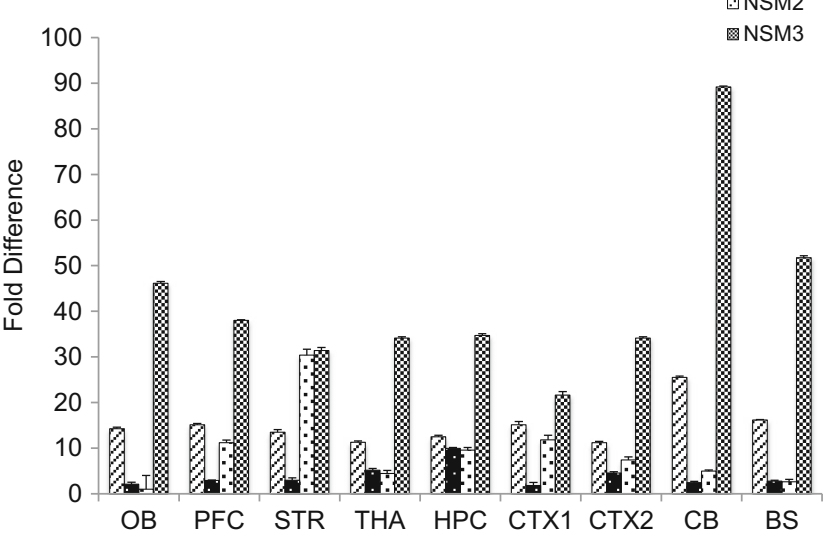

Fig. 1 Real-time RT-PCR analyses of A-SMase (ASM), nSMase 1 (NSM1), nSMase 2 (NSM2), nSMase 3 (NSM3) mRNA distribution in various parts of the rat brain including olfactory bulb $(\mathrm{OB})$, prefrontal cortex (PFC), striatum (STR), thalamus/hypothalamus (THA), hippocampus (HPC), cortex 1 (CTX1), cortex 2 (CTX2), cerebellum (CB), and brainstem (BS). Values were normalized to the lowest expressing nSMase 2 in the olfactory bulb. Data represents the mean and standard error from $n=6$ Wistar rats 
positioned at one end of the beam with the animal's home cage, bedding material, and food pellets at the opposite end. Rats were trained 2 days prior to the day of testing. During the training period, rats were encouraged to cross the beam by gentle nudging. Training trials were performed repeatedly until each animal successfully traversed the beam three times without pausing or turning around. On the day of testing, a baseline recording of three trials per rat was performed before intrastriatal injection of GW4869 or saline. Six hours after injection, rats were made to cross the beam for three trials. Trials where the rat spent more than $60 \mathrm{~s}$ to cross or fell from the beam were recorded as $60 \mathrm{~s}$. Trials where the rat paused or turned around were repeated. The average of the trials was recorded. The same testing procedure was performed for 5 days after intrastriatal injection of antisense or scrambled sense oligonucleotide. Possible significant differences were analyzed using Student's $t$ test. $P<0.05$ was considered significant.

A

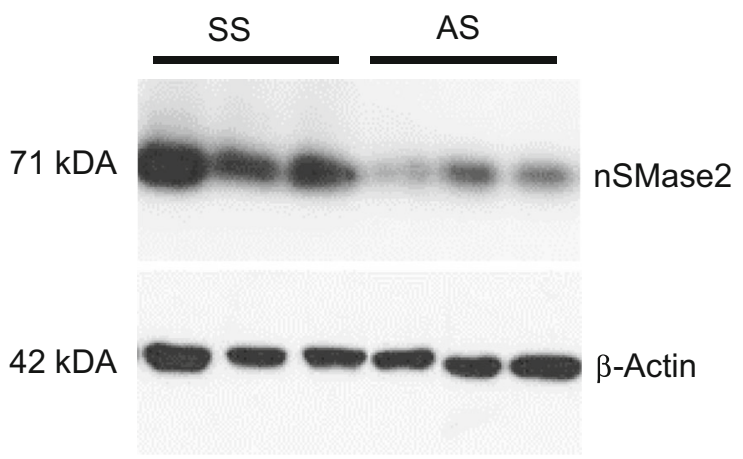

B

nSMase2 Protein Expression in the Striatum after Antisense Knockdown

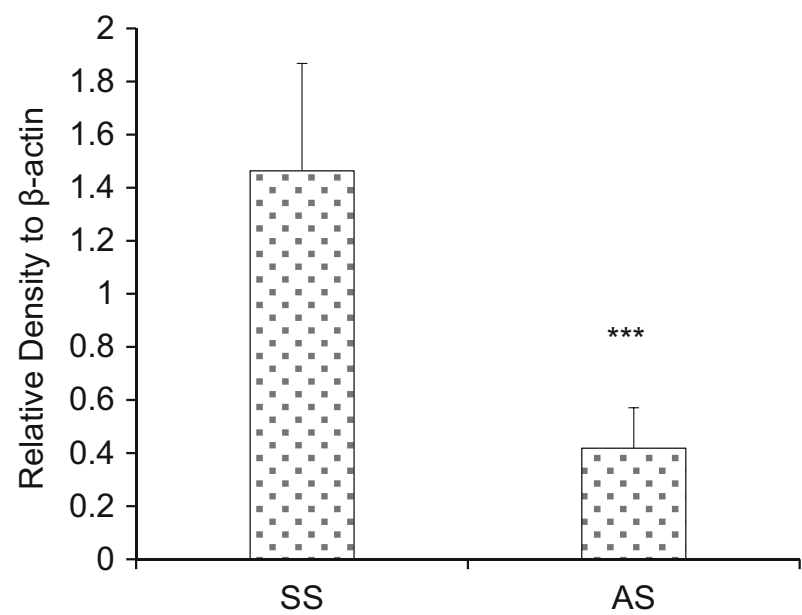

Fig. 2 a Immunoblot of the striatum of adult rats injected with scrambled sense nSMase2 (SS) and antisense nSMase2 (AS). Antisense knockdown of nSMase2 resulted in reduced density of the $71-\mathrm{kDa}$ band, indicating effectiveness of the knockdown, as well as specificity of the antibody. $\mathbf{b}$ Densitometric analysis of nSMase2 band intensities of SS- and ASinjected rats, normalized to $\beta$-actin. Data represents the mean and standard error from $n=6$ Wistar rats in each group. Each bar in the diagram indicates mean + SEM

\section{Acoustic Startle Reflex Test}

Startle reflex testing was conducted $6 \mathrm{~h}$ after surgery, using a startle chamber that contained a transparent Plexiglas tube mounted on a Plexiglas frame (SR-LAB, San Diego Instruments, San Diego, CA, USA)(Table 2). A high-frequency loudspeaker located in the chamber emits an uninterrupted background noise of $65 \mathrm{~dB}$ and the various acoustic stimuli. Vibrations from the Plexiglas cylinder as a result of the whole body startle response of the rats were transduced into analog signals $(0-10,000-\mathrm{mV}$ range) recorded by the load cell platform. The signals were digitized and analyzed using SR-LAB Startle Response Software (San Diego Instruments, San Diego, CA, USA). The protocol for measuring prepulse inhibition is based on a previous study [33]. The startle session proceeded after a 5min acclimatization period in the tube with a background noise level of $65 \mathrm{~dB}$ that was sustained for the entire startle session. Animals were then exposed to a succession of 32 discrete trials comprising of 1740 -ms presentations of a $120-\mathrm{dB}$ pulse (pulsealone), five 20 -ms presentations of each prepulse intensity (69, $73,77 \mathrm{~dB}) 100 \mathrm{~ms}$ prior to a $40-\mathrm{ms}$ presentation of a $120-\mathrm{dB}$ pulse (prepulse + pulse). No-stimulus trials, whereby no acoustic pulse was delivered, were also recorded to evaluate general

\section{A PFC STR THA HPC CB BS}

$71 \mathrm{kDA}$

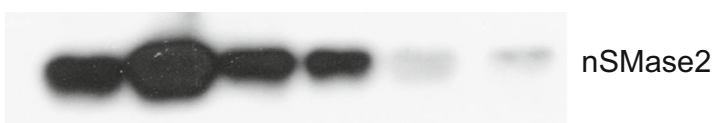

$42 \mathrm{kDA}$

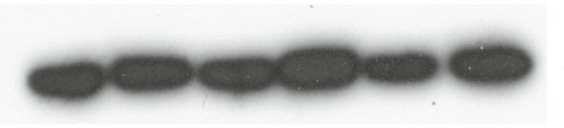

$\beta$-Actin

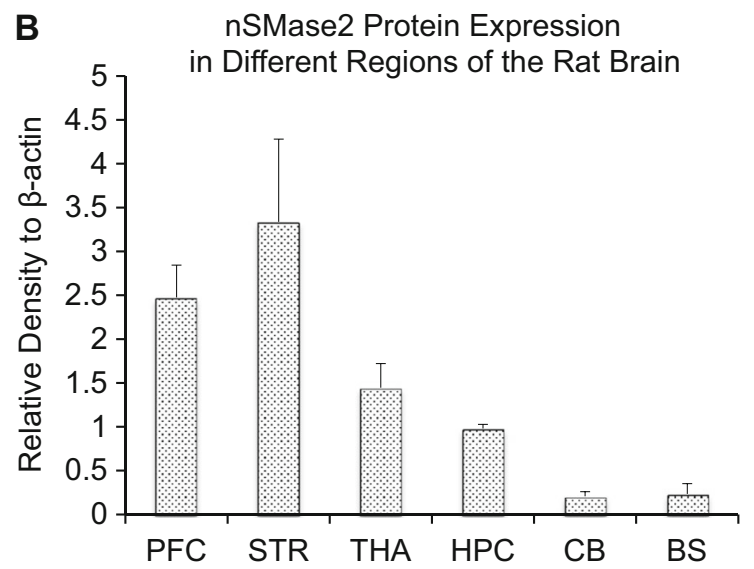

Fig. 3 a Immunoblot of adult rats in selected parts of the rat brain including the prefrontal cortex (PFC), striatum (STR), thalamus (THA), hippocampus (HPC), cerebellum (CB), and brainstem (BS). The striatum was found to have the highest nSMase 2 protein expression, followed by the prefrontal cortex, thalamus, hippocampus, brainstem, and cerebellum. b Densitometric analysis of nSMase 2 band intensities, normalized to $\beta$ actin. Data represents the mean and standard error from $n=4$ Wistar rats. Each bar in the diagram indicates mean + SEM 
motor activity of the animals. The pulse and prepulse stimuli used were in the form of a sudden elevation in broadband white noise level from background ( $65 \mathrm{~dB})$, and trials were conducted in pseudorandom order. Startle magnitude was calculated based on the pulse-alone $(120 \mathrm{~dB})$ trials and the prepulse + pulse trials. Percentage prepulse intensities (\%PPI) for the three prepulse intensities were derived using the formula: \%PPI $=$ (pulsealone - prepulse + pulse $) /($ pulse-alone $) \times 100 \%$. Possible significant differences were analyzed using Student's $t$ test. $P<0.05$ was considered significant.

\section{TUNEL and DAPI Histochemistry}

Four sets of rats injected with GW4869 or vehicle control from the acoustic startle reflex experiment were sacrificed 1 day after experiment, to determine if GW4869 inhibition of nSMase2 led to cell death. Animals were anesthetized deeply and perfused through the left cardiac ventricle with Ringer's solution followed by $4 \%$ paraformaldehyde in $0.1 \mathrm{M}$ phosphate buffer ( $\mathrm{pH}$ 7.4). The brains were harvested and sectioned coronally at $20 \mu \mathrm{m}$ using a cryostat. Sections were mounted on slides coated with gelatin and observed using a microscope to locate the needle track from intrastriatal injections to establish the plane for TUNEL staining. Sections were made permeable with $0.1 \%$ Triton X-100 and $0.1 \%$ sodium citrate in PBS for 10 min on ice. TUNEL staining was done with In-Situ Cell Death Detection Kit, Fluorescein (Roche Diagnostics, Basel, Switzerland) to identify DNA fragmentation, according to the manufacturer's protocol. The nuclear counterstaining and mounting agent used was ProLong ${ }^{\circledR}$ Gold Anti-fade reagent with DAPI (Invitrogen, Waltham, USA). Positive controls were incubated with
Fig. 4 Light micrographs of control and nSMase2-

immunolabeled sections of the rat CNS. a Control section from the striatum which had been incubated with PBS instead of primary antibody, showing absence of staining. b Low magnification showing the dorsal striatum (caudate-putamen, CPU) and globus pallidus (GP). White matter tracts such as the corpus callosum (CC) are unlabeled. c Moderately dense staining is found in the olfactory bulb (OB). d Moderately dense staining is found in the prefrontal cortex (PFC). III indicates layer III. e Dense staining is found in the form of puncta in the neuropil, in the caudate-putamen (CPU). $\mathbf{f}$ Light labeling is observe in the hippocampus. CA1, field CA1; SP, stratum pyramidale (SP). $\mathbf{g}$ Light labeling is found in the thalamus (TH). h Dense labeling is found in the dorsal horn (DH) of the spinal cord. Scale: a, c$\mathbf{h}=200 \mu \mathrm{m} . \mathbf{b}=2 \mathrm{~mm}$
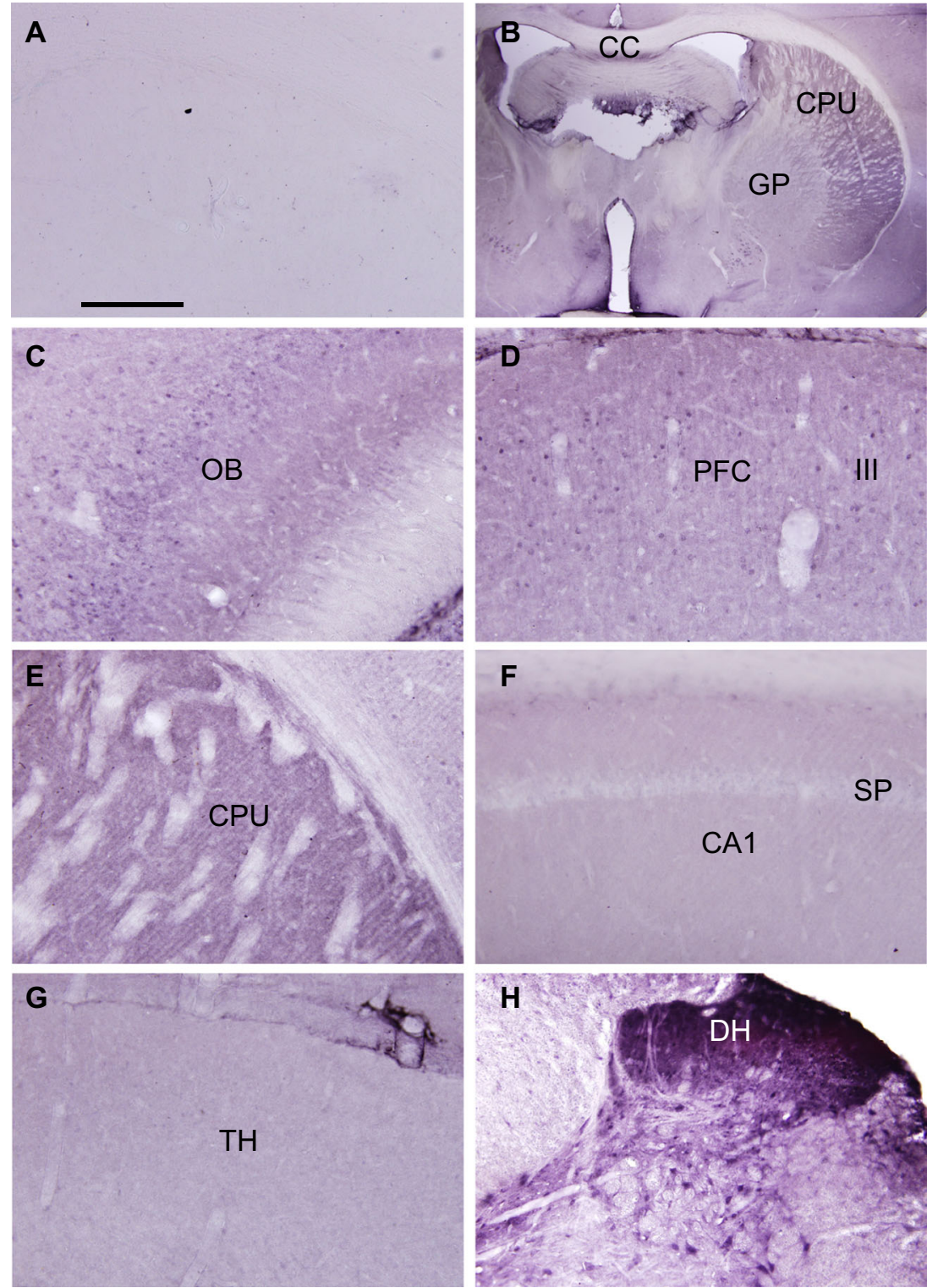
DNase I (3 U/ $/$ l) (Roche Diagnostics) for $10 \mathrm{~min}$ at room temperature. Sections were examined with an Olympus BX51 microscope (Olympus, Tokyo, Japan).

\section{Results}

\section{Differential mRNA Expression of SMase Isoforms in the CNS}

The mRNA expression of different sphingomyelinase isoforms was quantified by real-time RT-PCR, to determine their relative expression in the brain. nSMase 3 , acid sphingomyelinase, and nSMase2 were found to have higher expression than nSMase 1 in the brain (Fig. 1). However, since other studies measuring nSMase activity have raised the possibility that nSMase 3 activity may differ from that of other nSMases [34], and nSMase3 does not share any sequence homology or common catalytic core residues with other nSMase isoforms [8], nSMase2 was chosen for further analysis in this study.

\section{Expression of nSMase2 in Different Brain Regions at mRNA, Protein, and Cellular and Subcellular Levels}

Comparison of mRNA level of nSMase2 in different regions of the CNS showed that expression was highest in the striatum, followed by the prefrontal cortex, hippocampus, cortex 1 (which includes the primary and secondary motor cortex and primary somatosensory cortex), cortex 2 (which includes the parietal association cortex and secondary auditory cortex), cerebellum, thalamus, brainstem, and olfactory bulb (Fig. 1).

The protein expression of nSMase2 in different brain regions was then determined. Western blotting with nSMase2 antibody detected a single $71-\mathrm{kDa}$ band in the adult rat brain, consistent with the expected molecular weight of full length nSMase2 protein. Antisense knockdown of nSMase2 resulted in reduced density of the $71-\mathrm{kDa}$ band, indicating effectiveness of the knockdown, as well as specificity of the antibody (Fig. 2). The striatum had the highest level of nSMase2 protein expression, followed by the prefrontal cortex, thalamus, hippocampus, brainstem, and cerebellum (Fig. 3a, b).

The cellular distribution of nSMase2 was next elucidated (Fig. 4). Control sections incubated with PBS instead of primary antibody showed absence of immunostaining (Fig. 4a), while parts of the brain were labeled in sections incubated with nSMase 2 antibody (Fig. 4b). Dense labeling was observed in the striatum, including the caudate-putamen (Fig. 4b, e), while moderately dense staining was found in the olfactory bulb (Fig. 4c) and cerebral neocortex (Fig. 4d). The hippocampus (Fig. 4f) and thalamus (Fig. 4g) were lightly stained. Dense staining was found in the cochlear nuclei and dorsal horn of the spinal cord (Fig. 4h). The labeling pattern took the form of puncta in the neuropil, and cell outlines were indistinct. White matter tracts were very lightly labeled or unlabeled.

The subcellular localization of nSMase 2 was further examined (Fig. 5). Electron microscopy of nSMase2immunolabeled sections of the caudate-putamen showed that immunoreaction product was present in small diameter dendrites or dendritic spines, that formed asymmetrical synapses with unlabeled axon terminals containing small round vesicles, and characteristics of glutamatergic axons (Fig. 5a, b). The dendrites are putatively identified as those of medium spiny neurons in the caudate-putamen, and the axon terminals, as that of glutamatergic axons from the motor cortex.

\section{Alteration of Striatal Sphingolipids Due to Intrastriatal Inhibition of nSMase}

Lipidomic analysis showed significant increases in long chain sphingomyelin species $36: 1$ and 38:1 after intrastriatal injection of GW4869 indicating effectiveness of the inhibitor (Fig. 6). However, there was an absence of change in their
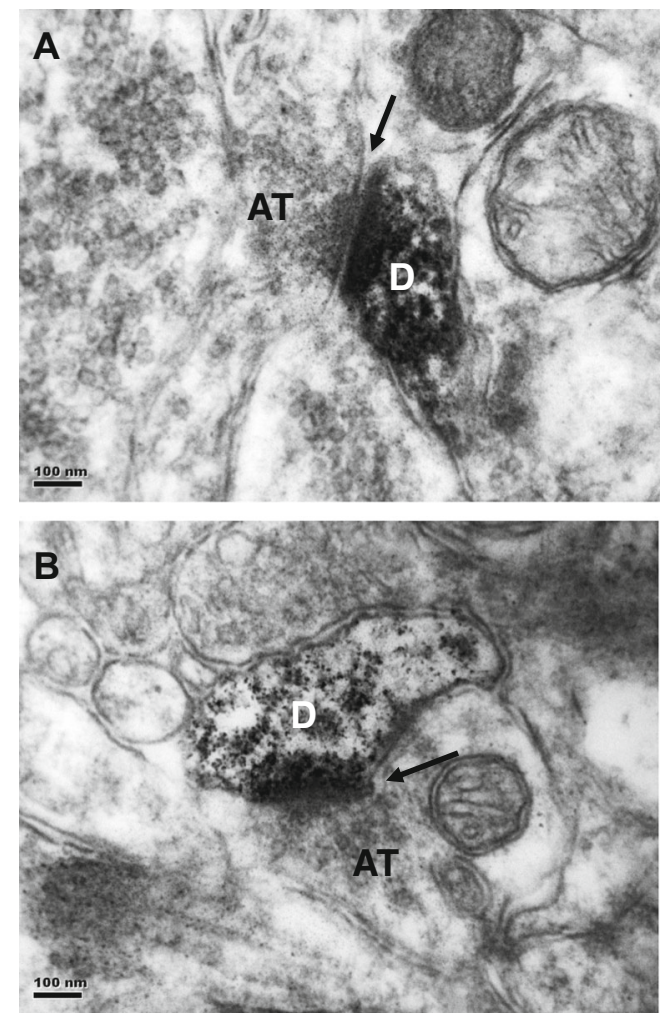

Fig. 5 a, b Electron micrographs of nSMase2-immunolabeled sections of the striatum. Immunoreaction product is present in small diameter dendrites or dendritic spines (D) which forms asymmetrical synapses (arrows) with unlabeled axon terminals (AT). The dendrites are putatively identified as those of medium spiny neurons in the striatum, and axon terminals, as glutamatergic axons that project from the motor cortex. Scale $=100 \mathrm{~nm}$ 
Fig. 6 Lipidomic analysis of lipid raft fractions. a, b Quantitation of 34:1 sphingomyelin and its corresponding ceramide species. There is no significant difference between vehicle- and GW4869 nSMase inhibitor-treated groups. c-f Quantitation of longer chain 36:1 and 38:1 sphingomyelins and their corresponding ceramides. Sphingomyelins, but not ceramides, were significantly reduced by inhibitor treatment. Asterisks indicate significant differences compared to controls $* p<0.05$
A

SM 34:1

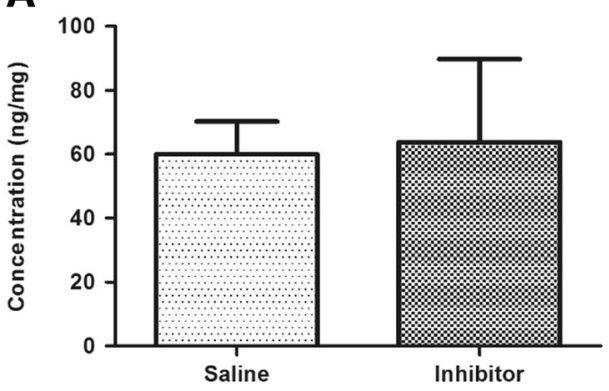

C

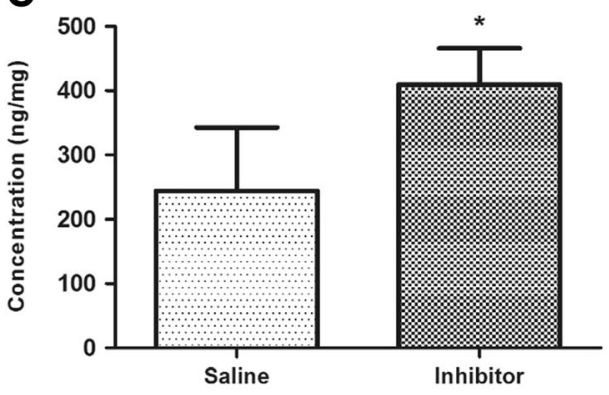

E

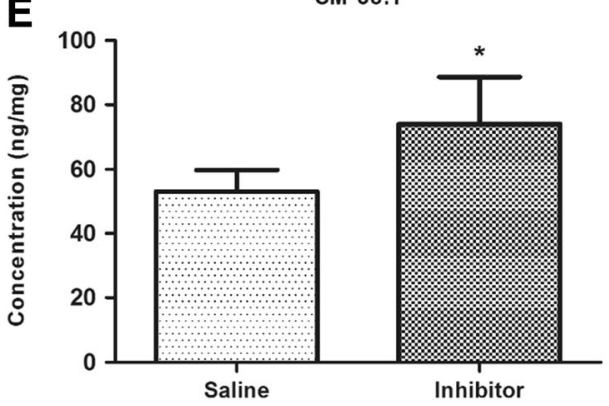

B

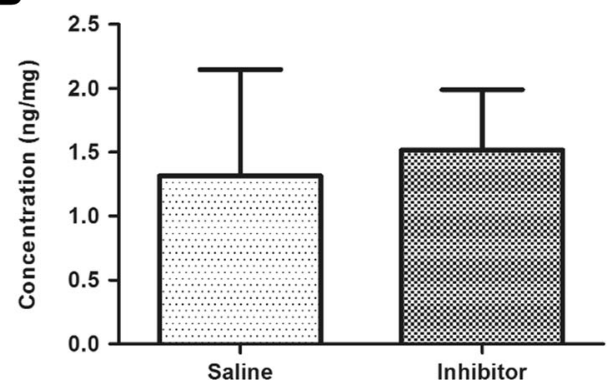

D

Cer d18:1/C18:0

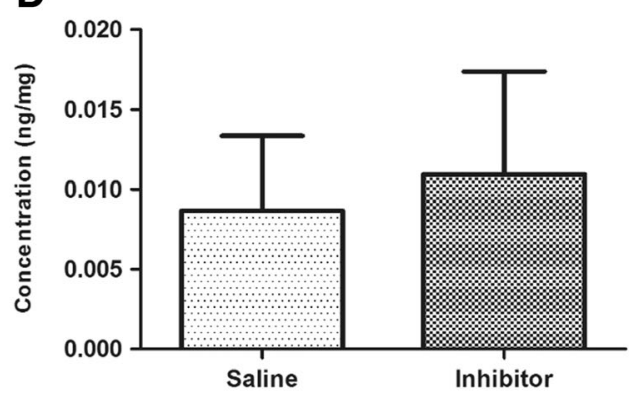

$\mathbf{F}$

Cer d18:1/C20:0

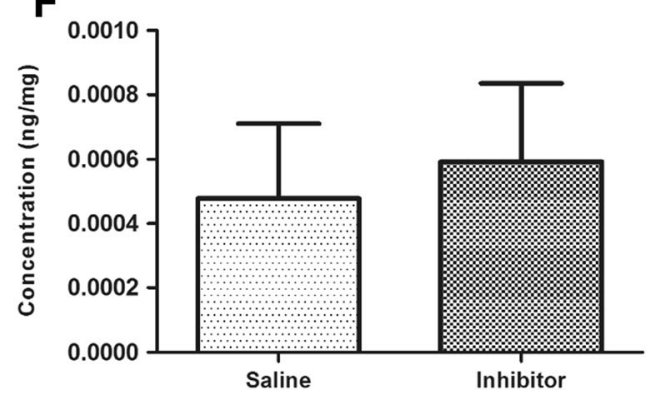

corresponding ceramides. There was also an absence of change in another sphingomyelin species 34:1 (Fig. 6). Results showed that nSMase inhibition causes accumulation in certain long chain sphingomyelin species, but does not affect total ceramide levels.

\section{Alteration of Striatal Lipid Raft Proteome after Intrastriatal Inhibition or Knockdown of nSMase2}

A total of 1423 high-confidence proteins were identified by proteomic profiling, with multiple peptides and $<1 \%$ FDR. We used a cutoff ratio value of 0.5 for downregulated and ratio value of 2 as upregulated proteins, i.e., 2-fold change. We identified a total of 269 downregulated proteins in lipid rafts of the striatum after nSMase 2 antisense injection to the caudate-putamen, while a total of 383 proteins were downregulated after GW4869 injection. The common downregulated proteins in both treatment groups are listed in Table 3. Surprisingly, no common upregulated protein was identified. Results are consistent with the notion that nSMase 2 activity is important for the aggregation or clustering of proteins in lipid rafts. A protein, annexin A6, was downregulated by 9-fold and 16-fold in the nSMase 2 antisense and inhibitor injection group, respectively. Annexin 6 is present in lipid rafts of synaptic membranes [35]. It regulates plasma membrane remodeling of lipid rafts [36] and acts as a scaffold to link membrane microdomains with the cytoskeleton [37]. Other proteins that showed decreases after nSMase2 inhibition or antisense treatment include hippocalcin, which has been localized to Lewy bodies [38], N-myc downstream-regulated gene 1 (NDRG1), and carbonyl reductase 1 .

\section{Rotarod Test}

Rats injected with GW4869 in the striatum remained on the rotarod for a significantly shorter period of time, as compared to saline-injected controls $(p<0.05)$ (Fig. 7a). Likewise, rats injected with antisense nSMase2 oligonucleotide remained on the rotarod for a significantly shorter period of time, as compared to scrambled sense-injected controls $(p<0.05)$ (Fig. 8a). 
Table 3 Proteins decreased in lipid raft fractions of rats injected with GW4869 nSMase inhibitor (Inb) or saline (Sal); or antisense (AS) vs. scrambled sense (SS)

\begin{tabular}{|c|c|c|c|c|}
\hline Gene symbol & Name & Pro_Mass & $\mathrm{AS} / \mathrm{SS}$ & $\mathrm{Inb} / \mathrm{Sal}$ \\
\hline Eef2 & Elongation factor 2 & 96192 & 0.082391 & 0.356 \\
\hline Anxa6 & Annexin & 76108 & 0.105078 & 0.061913 \\
\hline $\operatorname{Prdx} 5$ & Isoform cytoplasmic + peroxisomal of peroxiredoxin- 5 , mitochondrial & 17195 & 0.115124 & 0.253253 \\
\hline Lonp1 & Lon protease homolog, mitochondrial & 106296 & 0.139431 & 0.267 \\
\hline Aars & Alanine-tRNA ligase, cytoplasmic & 107522 & 0.139431 & 0.4005 \\
\hline Hpca & Neuron-specific calcium-binding protein hippocalcin & 22527 & 0.174288 & 0.205385 \\
\hline LOC100361259 & $60 \mathrm{~S}$ ribosomal protein $\mathrm{L} 13$ & 24168 & 0.179974 & 0.492118 \\
\hline Ctnna1 & Catenin (cadherin-associated protein), alpha 1 & 100858 & 0.18126 & 0.4984 \\
\hline Spr & RCG56371 & 28510 & 0.185908 & 0.34176 \\
\hline Ssrp1 & FACT complex subunit SSRP1 & 81206 & 0.185908 & 0.438154 \\
\hline Ndrg1 & Protein NDRG & 43383 & 0.193344 & 0.167529 \\
\hline Anxa7 & Annexin & 50272 & 0.2014 & 0.237333 \\
\hline Cbr1 & Carbonyl reductase [NADPH] 1 & 30920 & 0.210555 & 0.248121 \\
\hline Corolc & Coronin & 53828 & 0.220765 & 0.328615 \\
\hline Dpp6 & Dipeptidyl aminopeptidase-like protein 6 & 91842 & 0.2226 & 0.412211 \\
\hline Celf2 & CUGBP Elav-like family member 2 & 54291 & 0.231018 & 0.397882 \\
\hline Oxr1 & Oxidation resistance protein 1 & 97418 & 0.232385 & 0.323636 \\
\hline Gng3 & Guanine nucleotide-binding protein subunit gamma & 8527 & 0.250224 & 0.294869 \\
\hline $\mathrm{H} 3 \mathrm{f} 3 \mathrm{~b}$ & Histone H3 & 15376 & 0.255078 & 0.441192 \\
\hline A0A0G2JTG1 & Uncharacterized protein & 9382 & 0.256959 & 0.286437 \\
\hline Park7 & Park7 protein & 23002 & 0.260142 & 0.44144 \\
\hline Tsg101 & Tumor susceptibility gene 101 & 44221 & 0.264338 & 0.3115 \\
\hline Fkbp1a & Peptidyl-prolyl cis-trans isomerase FKBP1A & 11972 & 0.270931 & 0.462391 \\
\hline Frrs11 & DOMON domain-containing protein FRRS1L & 32892 & 0.271452 & 0.314986 \\
\hline Hist1h4b & Histone H4 & 11360 & 0.27173 & 0.416595 \\
\hline Pabpc1 & Polyadenylate-binding protein 1 & 60149 & 0.27189 & 0.408525 \\
\hline Rpl24 & 60 S ribosomal protein L24 & 17779 & 0.273329 & 0.196058 \\
\hline Chchd6 & MICOS complex subunit Mic25 & 29592 & 0.2736 & 0.449684 \\
\hline A0A0G2KBA1 & Uncharacterized protein & 31964 & 0.274636 & 0.319673 \\
\hline Erp29 & Endoplasmic reticulum resident protein 29 & 28614 & 0.274636 & 0.323636 \\
\hline Pitpna & Phosphatidylinositol transfer protein alpha isoform & 32059 & 0.276925 & 0.209412 \\
\hline Actn3 & Actin in alpha 3, isoform CRA_a & 103575 & 0.278862 & 0.4272 \\
\hline Lancl2 & LanC lantibiotic synthetase component C-like 2 (bacterial) & 51677 & 0.278862 & 0.4628 \\
\hline Ube2n & Ubiquitin-conjugating enzyme E2 N & 17170 & 0.281023 & 0.331163 \\
\hline Ndufs 7 & NADH dehydrogenase (ubiquinone) Fe-S protein 7 & 24215 & 0.28196 & 0.212085 \\
\hline Blvrb & Biliverdin reductase B (flavin reductase (NADPH)) & 22194 & 0.283219 & 0.33375 \\
\hline Dynll2 & Dynein light chain 2 , cytoplasmic & 10457 & 0.283631 & 0.366812 \\
\hline Atp5j2 & ATP synthase subunit $f$, mitochondrial & 10503 & 0.283934 & 0.368729 \\
\hline Rab7a & Ras-related protein Rab-7a & 21361 & 0.284329 & 0.440145 \\
\hline Sdhb & Succinate dehydrogenase [ubiquinone] iron-sulfur subunit, mitochondrial & 32607 & 0.287714 & 0.090127 \\
\hline Canx & Calnexin & 67612 & 0.287714 & 0.237333 \\
\hline Pdxp & Pyridoxal phosphate phosphatase & 33380 & 0.287714 & 0.339048 \\
\hline $\mathrm{Cdc} 42$ & Cell division control protein 42 homolog & 21696 & 0.292945 & 0.146051 \\
\hline Cars & Cysteinyl-tRNA synthetase (predicted), isoform CRA_b & 86110 & 0.3021 & 0.237333 \\
\hline Cacnb2 & Calcium channel, voltage-dependent, beta 2 subunit, isoform CRA_d & 68596 & 0.3021 & 0.237333 \\
\hline Ppp2r5b & Protein LOC100909468 & 57746 & 0.3021 & 0.34176 \\
\hline Lrrc7 & Leucine-rich repeat-containing protein 7 & 168690 & 0.3021 & 0.356 \\
\hline $\operatorname{Ddx} 5$ & DEAD (Asp-Glu-Ala-Asp) box polypeptide 5 & 69709 & 0.3021 & 0.356 \\
\hline
\end{tabular}


Table 3 (continued)

\begin{tabular}{|c|c|c|c|c|}
\hline Gene symbol & Name & Pro_Mass & $\mathrm{AS} / \mathrm{SS}$ & $\mathrm{Inb} / \mathrm{Sal}$ \\
\hline Atad3 & ATPase family AAA domain-containing protein 3 & 66889 & 0.3021 & 0.356 \\
\hline Gad2 & Glutamate decarboxylase 2 & 66215 & 0.3021 & 0.356 \\
\hline Sacm11 & Phosphatidylinositide phosphatase SAC1 & 67509 & 0.3021 & 0.356 \\
\hline Clip2 & CAP-Gly domain-containing linker protein 2 & 115975 & 0.3021 & 0.356 \\
\hline Aldh2 & Aldehyde dehydrogenase, mitochondrial & 56994 & 0.314688 & 0.303787 \\
\hline Uqcr10 & Protein Uqcr10 & 7095 & 0.318671 & 0.150211 \\
\hline Pdia3 & Protein disulfide-isomerase & 57499 & 0.3192 & 0.322415 \\
\hline Suclg1 & Succinate-CoA ligase, GDP-forming, alpha subunit, isoform CRA_b 1 & 37935 & 0.336958 & 0.4628 \\
\hline Pacsin 1 & Protein kinase $\mathrm{C}$ and casein kinase substrate in neurons protein 1 & 50760 & 0.342924 & 0.201217 \\
\hline Atp5o & ATP synthase subunit $\mathrm{O}$, mitochondrial & 23440 & 0.344484 & 0.277985 \\
\hline Btbd8 & Protein Btbd8 & 149108 & 0.345257 & 0.4005 \\
\hline Rpl30 & $60 \mathrm{~S}$ ribosomal protein $\mathrm{L} 30$ & 12947 & 0.355412 & 0.418824 \\
\hline $\operatorname{Idh} 3 \mathrm{~B}$ & Isocitrate dehydrogenase $[\mathrm{NAD}]$ subunit beta, mitochondrial & 42612 & 0.358744 & 0.459717 \\
\hline Hnrnpab & CArG-binding factor A & 30948 & 0.359643 & 0.32752 \\
\hline Ube2o & Protein Ube2o & 126509 & 0.36252 & 0.4272 \\
\hline Pcdh1 & Protein Pcdh1 & 129114 & 0.36252 & 0.4272 \\
\hline Fam49a & Family with sequence similarity 49 , member A & 37704 & 0.366182 & 0.2581 \\
\hline $\operatorname{Cox} 6 \mathrm{c} 2$ & Cytochrome c oxidase subunit $6 \mathrm{C}-2$ & 8449 & 0.368122 & 0.279335 \\
\hline Cryab & Alpha-crystallin B chain & 20076 & 0.368664 & 0.434441 \\
\hline Hspa5 & 78-kDa glucose-regulated protein & 72473 & 0.369559 & 0.42417 \\
\hline Sfpq & Protein Sfpq & 75210 & 0.372804 & 0.188075 \\
\hline Gsta1 & Glutathione S-transferase & 25360 & 0.375947 & 0.3115 \\
\hline Rac1 & Ras-related $\mathrm{C} 3$ botulinum toxin substrate 1 & 24636 & 0.384326 & 0.229125 \\
\hline Pip4k2b & Phosphatidylinositol 5-phosphate 4-kinase type-2 beta & 47633 & 0.384491 & 0.453091 \\
\hline Dnm11 & Dynamin-1-like protein & 84369 & 0.387066 & 0.460283 \\
\hline Ccsap & Protein Ccsap & 28584 & 0.387308 & 0.34176 \\
\hline $\operatorname{Cct} 5$ & T-complex protein 1 subunit epsilon & 59955 & 0.390953 & 0.326333 \\
\hline Ehd3 & EH domain-containing protein 3 & 60810 & 0.390953 & 0.403467 \\
\hline Scrn1 & Secernin-1 & 46994 & 0.394043 & 0.1246 \\
\hline Lynx 1 & Ly6/neurotoxin 1 (predicted), isoform CRA_a & 13396 & 0.395996 & 0.466649 \\
\hline P11517 & Hemoglobin subunit beta-2 & 16086 & 0.4028 & 0.165568 \\
\hline Map4 & Microtubule-associated protein & 235075 & 0.4028 & 0.2848 \\
\hline Hnrnpm & Isoform 2 of heterogeneous nuclear ribonucleoprotein $\mathrm{M}$ & 56864 & 0.4028 & 0.474667 \\
\hline Wdr13 & Protein Wdr13 & 43571 & 0.4028 & 0.258909 \\
\hline Epn2 & Epsin 2 & 68809 & 0.4028 & 0.474667 \\
\hline Atp1a2 & Sodium/potassium-transporting ATPase subunit alpha- 2 & 113457 & 0.415242 & 0.495857 \\
\hline LOC684681 & Protein LOC684681 & 21304 & 0.415388 & 0.109045 \\
\hline Pabpc4 & Polyadenylate-binding protein & 71188 & 0.42294 & 0.459355 \\
\hline Atp4a & Sodium/potassium-transporting ATPase subunit alpha & 115674 & 0.435024 & 0.4272 \\
\hline Mog & Myelin-oligodendrocyte glycoprotein & 28153 & 0.441366 & 0.363574 \\
\hline Nono & Non-POU domain-containing octamer-binding protein & 55005 & 0.441531 & 0.449684 \\
\hline $\mathrm{Phb} 2$ & Prohibitin-2 & 33148 & 0.444169 & 0.452486 \\
\hline Rhob & Rho-related GTP-binding protein RhoB & 22565 & 0.447108 & 0.37024 \\
\hline Ldha & L-lactate dehydrogenase & 36712 & 0.447414 & 0.415081 \\
\hline Syncrip & Heterogeneous nuclear ribonucleoprotein Q & 62861 & 0.447941 & 0.41296 \\
\hline Rtn4rl2 & Reticulon-4 receptor-like 2 & 46896 & 0.448277 & 0.260488 \\
\hline Gstm3 & Glutathione S-transferase $\mathrm{Yb}-3$ & 25835 & 0.45861 & 0.24935 \\
\hline Atp6v1c1 & V-type proton ATPase subunit C 1 & 44044 & 0.459392 & 0.388364 \\
\hline Palm & Paralemmin-1 & 42072 & 0.459717 & 0.356 \\
\hline
\end{tabular}


Table 3 (continued)

\begin{tabular}{|c|c|c|c|c|}
\hline Gene symbol & Name & Pro_Mass & AS/SS & $\mathrm{Inb} / \mathrm{Sal}$ \\
\hline Idh3a & Isocitrate dehydrogenase [NAD] subunit, mitochondrial & 41606 & 0.462791 & 0.33802 \\
\hline Acat1 & Acetyl-CoA acetyltransferase, mitochondrial & 45009 & 0.464422 & 0.458576 \\
\hline Rala & Ras-related protein Ral-A & 23709 & 0.468255 & 0.4094 \\
\hline Rpl10a & $60 \mathrm{~S}$ ribosomal protein $\mathrm{L} 10 \mathrm{a}$ & 24987 & 0.469334 & 0.439319 \\
\hline Msn & Moesin & 67899 & 0.469933 & 0.263704 \\
\hline Dlg2 & Disks large homolog 2 & 95331 & 0.474729 & 0.3204 \\
\hline Fam49b & Fam $49 b$ protein & 37038 & 0.477949 & 0.251655 \\
\hline Alb & Serum albumin & 70682 & 0.48336 & 0.246206 \\
\hline Tppp & Protein Tppp & 25738 & 0.48336 & 0.362473 \\
\hline Mapk1 & Mitogen-activated protein kinase 1 & 41648 & 0.48336 & 0.4895 \\
\hline
\end{tabular}

Proteins that were reduced by more than $50 \%$ by both genetic and pharmacological inhibition of nSMase 2 are listed

\section{Beam Crossing Test}

Rats exhibited poorer performance on the beam crossing test after intrastriatal injection of GW4869. These were unable to place both hind paws on the horizontal surface of the beam but attempted to balance and traverse the beam by placing their forepaw on the horizontal surface and dragging themselves across the beam, before losing balance and falling off the beam. They were unable to successfully cross the beam in all except one trial (Fig. 7b). Rats injected with vehicle control showed no significant difference in performance before and after injection. There was no significant difference in time taken to cross the beam, between the two groups, before injection. Rats injected with antisense oligonucleotides to nSMase2 showed significantly poorer performance in the balance beam test, compared to scrambled sense-injected controls $(p<0.05)$ (Fig. 8b).

\section{Acoustic Startle Reflex Test and Prepulse Inhibition of Acoustic Startle}

The amplitude of the acoustic startle response was first compared using pulse-alone trials. Rats that received GW4869 injection showed significantly decreased acoustic startle response compared to saline-injected controls (Fig. 9a). Prepulse inhibition (PPI) of the auditory startle response was also determined after GW4869 or saline injection. Rats that received GW4869 injection showed significantly increased PPI as compared to saline-injected controls (Fig. 9b).

\section{TUNEL and DAPI Histochemistry}

GW4869 treatment did not cause an increase in nuclear fragmentation in the TUNEL assay, while positive control sections displayed TUNEL-positive staining of the nuclei. Results imply that injected treatments did not cause the induction of cell death in the striatum (Supplementary Figure).

\section{Discussion}

nSMase 2 is the most well-studied mammalian nSMase of the sphingomyelinase family and has been shown to be mainly found in the brain [7, 39, 40]. Our real-time RT-PCR results showed that nSMase 2 mRNA is present in different brain regions, with the highest expression in the striatum, followed by the cerebral cortex and low expression in the brainstem and cerebellum. Western blots showed high levels of nSMase2 protein expression in the striatum and cortex and low expression in the brainstem and cerebellum, which is consistent with the RT-PCR results. The $71-\mathrm{kDa}$ band detected is in accordance with the molecular weight of full length nSMase2 [4] and was significantly reduced by antisense oligonucleotide knockdown in the striatum, indicating specificity of the antibody. Immunohistochemical analyses revealed dense staining in the striatum, cochlear nuclei, and dorsal horn of the spinal cord, and moderate staining in cerebral neocortex. White matter tracts such as the corpus callosum were very lightly labeled or unlabeled. The above results are in agreement with previous findings that nSMase activity is highest in the striatum among different regions in the human and rat brain-with activity in the stratum being 2.7 times greater than that of the parietal cortex, and 10 times that of the cerebellum, brainstem, and corpus callosum [28, 39]. Although our realtime RT-PCR results reveal high nSMase 3 expression across all brain regions including the brainstem and cerebellum, previous studies that measured nSMase enzymatic activity have failed to detect this trend [28]. nSMase3 does not share any sequence homology or catalytic core residues [8] and its activity may differ from other nSMases [34]. It is possible that nSMase 3 may have a different function from other isoforms in the brain.

Lipidomic analysis showed that SM36:1 and SM38:1 were increased after nSMase was blocked in the striatum, indicating effectiveness of the GW4869 nSMase inhibitor. However, there was an absence of change in another sphingomyelin species 
A

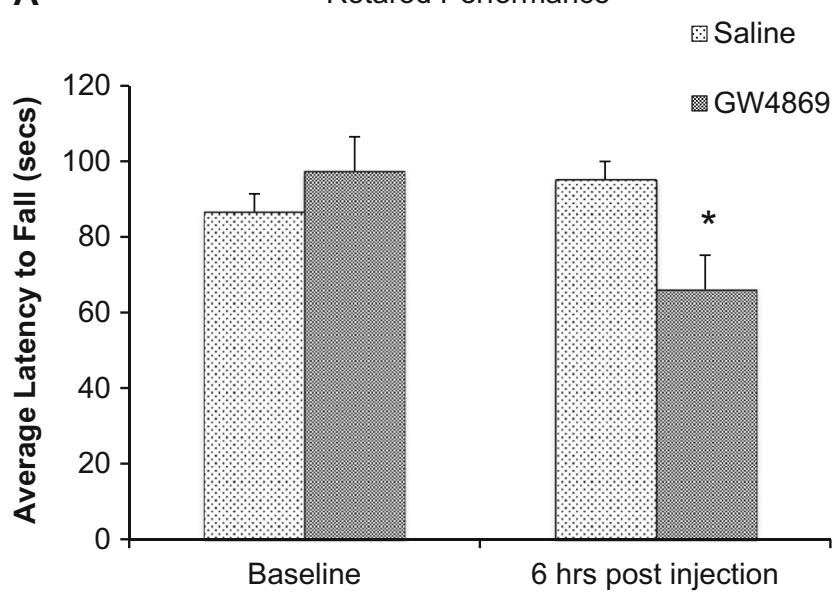

B

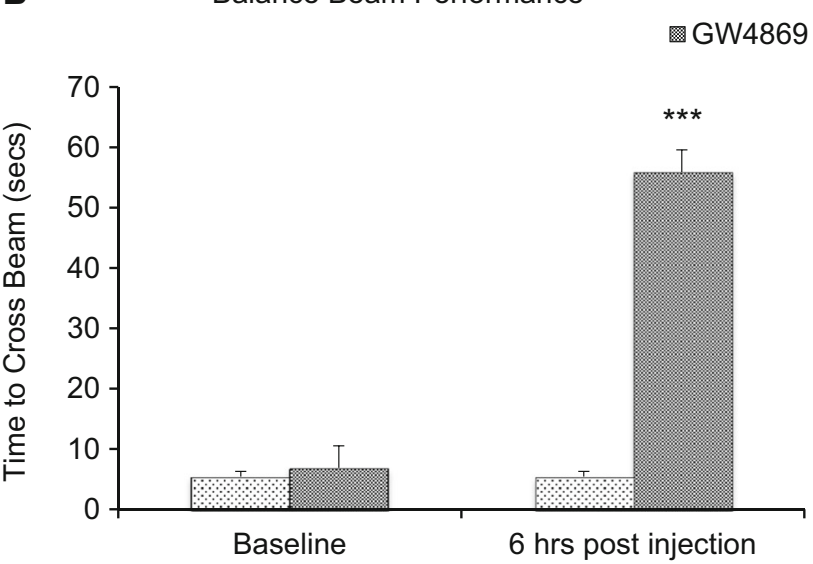

Fig. 7 a Rotarod performance (saline vs GW4869 nSMase inhibitor). Histograms represent the time spent by rats injected with saline and rats injected with GW4869 walking on the accelerating rotating rod. Animals were tested 6-h post intrastriatal injection. Data represents the mean and standard error from $n=6$ Wistar rats in each group. Each bar in the diagram indicates mean + SEM. b Beam crossing test (saline vs inhibitor). Histograms represent the time spent by rats injected with saline and rats injected with GW4860 to cross the beam. Rats that fell off the beam or were unable to cross the beam successfully after $60 \mathrm{~s}$ were given a maximum score of $60 \mathrm{~s}$. Animals were tested 6-h post intrastriatal injection. Data represents the mean and standard error from $n=6$ Wistar rats in each group. Each bar in the diagram indicates mean + SEM. Asterisks indicate significant differences compared to controls: $* p<0.05, * * p<0.01, * * * p<0.001$

34:1, consistent with previous reports that nSMase2 exhibits substrate preference for longer chain sphingomyelins [41]. Interestingly, an expected decrease in corresponding 36:1 and 38:1 ceramides was not observed. Results indicate that nSMase inhibition causes accumulation in certain sphingomyelin species by preventing breakdown into their corresponding ceramides. The unchanged ceramide levels after nSMase inhibition may be due to compensation from de novo sphingolipid synthesis, which is a major source of ceramide generation and the only source of non-dietary

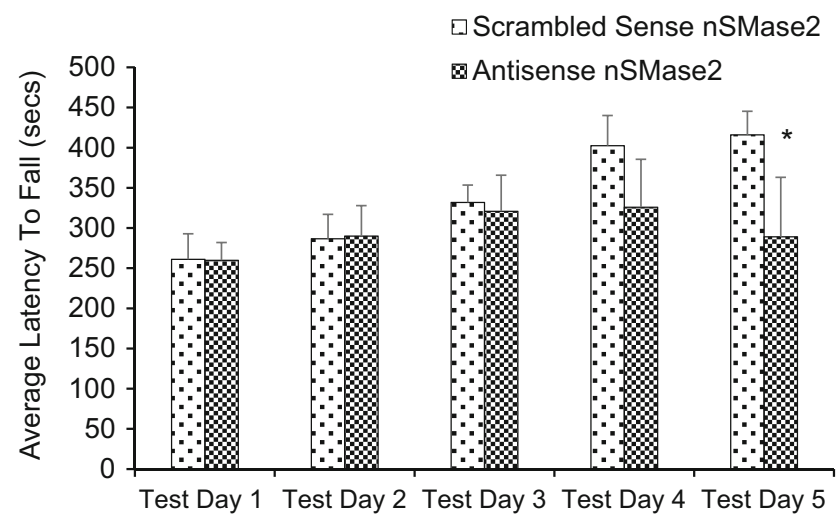

B

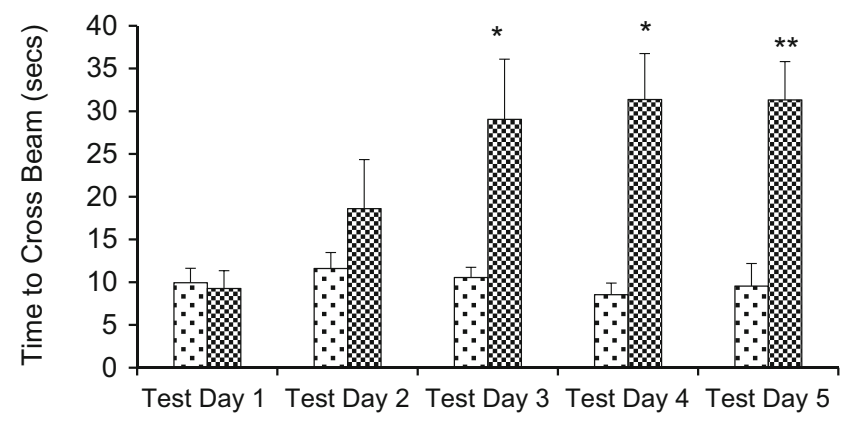

Fig. 8 a Rotarod performance (scrambled sense vs antisense). The histograms represent the time spent by rats injected with scrambled sense nSMase 2 and rats injected with antisense nSMase 2 walking on the accelerating rotating rod. Animals were tested for 5 days post intrastriatal injection. Data represents the mean and standard error from $n=6$ Wistar rats in each group. Each bar in the diagram indicates mean + SEM. b Beam crossing test (scrambled sense vs antisense). The histograms represent the time spent by rats injected with saline and rats injected with GW4860 to cross the beam. Rats that fell off the beam or were unable to cross the beam successfully after $60 \mathrm{~s}$ were given a maximum score of $60 \mathrm{~s}$. Animals were tested for 5 days post intrastriatal injection. Data represents the mean and standard error from $n=6$ Wistar rats in each group. Each bar in the diagram indicates mean + SEM. Asterisks indicate significant differences compared to controls: $* p<0.05, * * p<0.01, * * * p<0.001$

sphingolipids [42]. These findings suggest that sphingomyelin accumulation is the primary cause of the observed phenotype, and not the depletion of ceramides per se. Proteomic analyses showed significant decreases in many proteins due to inhibition or antisense knockdown of nSMase 2 in the striatum. This could have functional consequences due to changes in aggregation or clustering of these proteins. One of the proteins that showed decreases after antisense knockdown or inhibition of nSMase2 is annexin A6. This is a member of the annexin family of calcium-dependent membrane and phospholipidbinding proteins, which creates a scaffold for the formation of multifactorial signaling complexes and functions as an organizer of membrane domains to modulate intracellular 
A

Pulse-Only Response

$\square$ Saline 因 GW4869

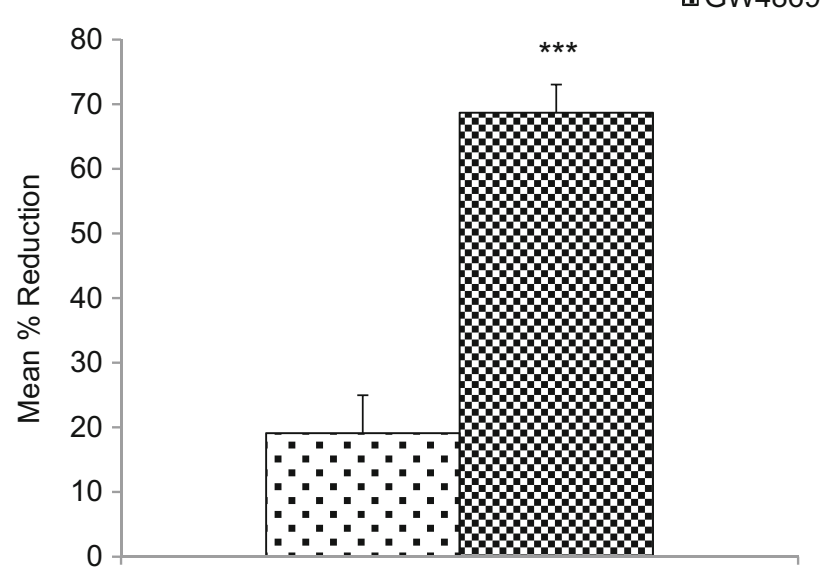

B

Prepulse Inhibition of Acoustic Startle Response

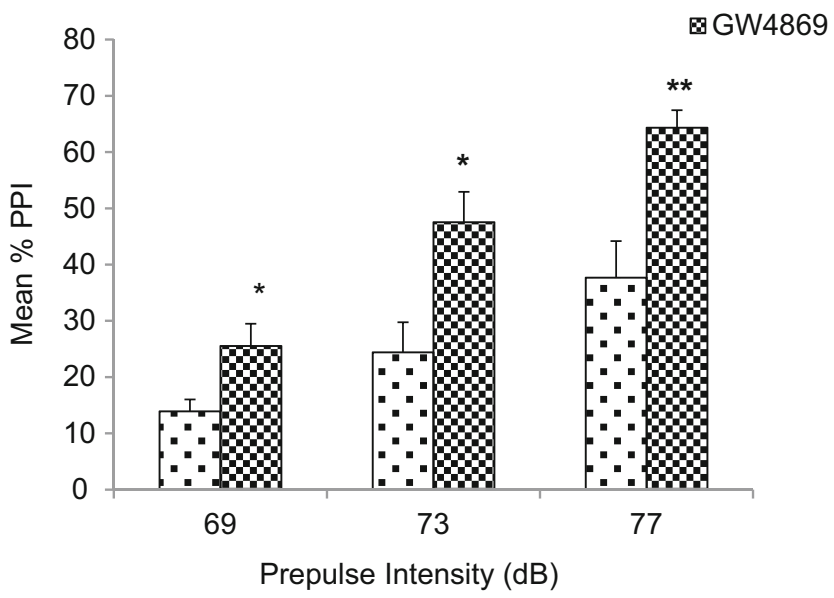

Fig. 9 a Acoustic startle reflex. Mean percentage differences in auditory startle response before treatment and after intrastriatal saline or GW4869 injection. The acoustic startle response test was conducted $6 \mathrm{~h}$ after saline or GW4869 intrastriatal injection. Data represents the mean and standard error from $n=6$ Wistar rats in each group. Each bar in the diagram indicates mean + SEM. b Prepulse inhibition. Prepulse inhibitions of the auditory startle response at three prepulse intensities after saline or GW4869 administration. The acoustic startle response test was conducted $6 \mathrm{~h}$ after saline or GW4869 intrastriatal injection. Data represents the mean and standard error from $n=6$ Wistar rats in each group. Each bar in the diagram indicates mean + SEM. Asterisks indicate significant differences compared to controls: $* p<0.05, * * p<0.01$, $* * * p<0.001$

cholesterol homeostasis, and regulates transient membraneactin interactions during endocytic and exocytic transport $[37,43]$.

The high level of expression of nSMase 2 in the striatum suggests that the enzyme may be important in the function of this brain region. We investigated the involvement of nSMase2 in motor function and coordination via intrastriatal injection of GW4869 a well-established specific inhibitor of nSMase2 that does not affect A-SMase activity [12, 23, 44-49], or antisense oligonucleotide to nSMase2. Rats that received intrastriatal injection of GW4869 or antisense oligonucleotide to nSMase2 showed impaired motor function in the rotarod test, and remained on the rotarod for a shorter duration compared to controls. Similarly, rats injected with GW4869 or antisense oligonucleotide displayed poorer motor coordination in the beam crossing test, with all rats falling off the beam and unable to successfully cross the beam. Results indicate an important role of nSMase 2 in regulation of motor activity and coordination [50]. A role of nSMase2 in the startle reflex and prepulse inhibition of startle was also investigated. Inhibition of nSMase 2 in the striatum resulted in decreased acoustic startle response and increased prepulse inhibition (\%PPI) compared to controls, indicating an improvement in sensorimotor gating. Besides the caudate-putamen or dorsal striatum, it is possible that nSMase 2 could have a role in the ventral striatum and the reward pathway, which extends from the ventral tegmental area to the nucleus accumbens shell [51]. This possibility needs to be investigated in future studies.

The exact molecular mechanisms of how nSMase2 plays a role in the regulation of striatal activity are not fully understood. Nevertheless, our EM finding that nSMase2 was present in small diameter dendrites or dendritic spines of asymmetrical synapses with unlabeled axon terminals that contained small round vesicles, and features of glutamatergic axons $[52,53]$, suggests that it may affect excitatory neurotransmission. Lipid rafts are docking sites for glutamate receptors [54-56], and nSMase 2 has been shown to regulate AMPA receptor numbers and NMDA glutamate receptor subunit composition and clustering [22, 23]. Long-term inhibition of nSMase2 increases PSD-95, as well as the amount of NMDA receptor NR2A subunits and AMPA receptor GluR1 subunits [23]. Knockout of the AMPA receptor subunit GluR1 results in increased level of dopamine in the striatum [57] and increased locomotion [58]. We postulate that nSMase2 could have a role in modulating glutamatergic transmission, and that enzyme inhibition could result in alterations in excitatory transmission at the corticostriatal synapse and decreased motor function. A change in excitatory transmission could also be consistent with the observed improvement in prepulse inhibition of the auditory startle response. Further work is necessary to determine the molecular mechanisms of nSMase 2 action in the brain, and possible changes in enzyme activity in neurological and psychiatric disorders.

Funding information This work was supported by grants from the National Medical Research Council and the National University Health System of Singapore.

Compliance with Ethical Standards All procedures were in accordance with the Principles of Laboratory Animal Care and approved by the Institutional Animal Care and Use Committee of the National University of Singapore. 
Conflict of Interest The authors declare that they have no conflict of interest.

Open Access This article is distributed under the terms of the Creative Commons Attribution 4.0 International License (http:// creativecommons.org/licenses/by/4.0/), which permits unrestricted use, distribution, and reproduction in any medium, provided you give appropriate credit to the original author(s) and the source, provide a link to the Creative Commons license, and indicate if changes were made.

\section{References}

1. Bielawska A, Linardic CM, Hannun YA (1992) Ceramidemediated biology. Determination of structural and stereospecific requirements through the use of N-acyl-phenylaminoalcohol analogs. J Biol Chem 267(26):18493-18497

2. Jayadev S, Liu B, Bielawska AE, Lee JY, Nazaire F, Pushkareva M, Obeid LM, Hannun YA (1995) Role for ceramide in cell cycle arrest. J Biol Chem 270(5):2047-2052

3. Jarvis WD, Kolesnick RN, Fornari FA, Traylor RS, Gewirtz DA, Grant S (1994) Induction of apoptotic DNA damage and cell death by activation of the sphingomyelin pathway. Proc Natl Acad Sci U S A 91(1):73-77

4. Clarke CJ, Snook CF, Tani M, Matmati N, Marchesini N, Hannun YA (2006) The extended family of neutral sphingomyelinases. Biochemistry 45(38):11247-11256. https://doi.org/10.1021/ bi061307z

5. Jenkins RW, Canals D, Hannun YA (2009) Roles and regulation of secretory and lysosomal acid sphingomyelinase. Cell Signal 21(6): 836-846

6. Shamseddine AA, Airola MV, Hannun YA (2015) Roles and regulation of neutral sphingomyelinase-2 in cellular and pathological processes. Adv Biol Regul 57:24-41. https://doi.org/10.1016/j. jbior.2014.10.002

7. Hofmann K, Tomiuk S, Wolff G, Stoffel W (2000) Cloning and characterization of the mammalian brain-specific, $\mathrm{Mg} 2+-$ dependent neutral sphingomyelinase. Proc Natl Acad Sci U S A 97(11):5895-5900

8. Krut O, Wiegmann K, Kashkar H, Yazdanpanah B, Kronke M (2006) Novel tumor necrosis factor-responsive mammalian neutral sphingomyelinase-3 is a C-tail-anchored protein. J Biol Chem 281(19):13784-13793. https://doi.org/10.1074/jbc.M511306200

9. Zeng C, Lee JT, Chen H, Chen S, Hsu CY, Xu J (2005) Amyloidbeta peptide enhances tumor necrosis factor-alpha-induced iNOS through neutral sphingomyelinase/ceramide pathway in oligodendrocytes. J Neurochem 94(3):703-712. https://doi.org/10.1111/j. 1471-4159.2005.03217.x

10. De Palma C, Meacci E, Perrotta C, Bruni P, Clementi E (2006) Endothelial nitric oxide synthase activation by tumor necrosis factor alpha through neutral sphingomyelinase 2, sphingosine kinase 1 , and sphingosine 1 phosphate receptors: a novel pathway relevant to the pathophysiology of endothelium. Arterioscler Thromb Vasc Biol 26(1):99-105. https://doi.org/10.1161/01.ATV.0000194074. 59584.42

11. Wascholowski V, Giannis A, Pitsinos EN (2006) Influence of the scyphostatin side chain on the mode of inhibition of neutral sphingomyelinase. ChemMedChem 1(7):718-721. https://doi.org/ 10.1002/cmdc. 200600099

12. Luberto C, Hassler DF, Signorelli P, Okamoto Y, Sawai H, Boros E, Hazen-Martin DJ, Obeid LM et al (2002) Inhibition of tumor necrosis factor-induced cell death in MCF7 by a novel inhibitor of neutral sphingomyelinase. J Biol Chem 277(43):41128-41139. https://doi.org/10.1074/jbc.M206747200
13. Figuera-Losada M, Stathis M, Dorskind JM, Thomas AG, Bandaru VV, Yoo SW, Westwood NJ, Rogers GW et al (2015) Cambinol, a novel inhibitor of neutral sphingomyelinase 2 shows neuroprotective properties. PLoS One 10(5):e0124481. https://doi.org/10.1371/ journal.pone. 0124481

14. Sawai H, Domae N, Nagan N, Hannun YA (1999) Function of the cloned putative neutral sphingomyelinase as lyso-platelet activating factor-phospholipase C. J Biol Chem 274(53):38131-38139

15. Lennarz WJ, Lane MD (2013) Encyclopedia of Biological Chemistry. Elsevier Science. Amsterdam, The Netherlands

16. Wu BX, Clarke CJ, Hannun YA (2010) Mammalian neutral sphingomyelinases: regulation and roles in cell signaling responses. NeuroMolecular Med 12(4):320-330. https://doi.org/10.1007/ s12017-010-8120-Z

17. Marchesini N, Osta W, Bielawski J, Luberto C, Obeid LM, Hannun YA (2004) Role for mammalian neutral sphingomyelinase 2 in confluence-induced growth arrest of MCF7 cells. J Biol Chem 279(24):25101-25111. https://doi.org/10.1074/jbc.M313662200

18. Karakashian AA, Giltiay NV, Smith GM, Nikolova-Karakashian MN (2004) Expression of neutral sphingomyelinase-2 (NSMase2) in primary rat hepatocytes modulates IL-beta-induced JNK activation. FASEB journal : official publication of the Federation of American Societies for Experimental Biology 18(9):968-970. https://doi.org/10.1096/fj.03-0875fje

19. Clarke CJ, Guthrie JM, Hannun YA (2008) Regulation of neutral sphingomyelinase-2 (nSMase2) by tumor necrosis factor-alpha involves protein kinase C-delta in lung epithelial cells. Mol Pharmacol 74(4):1022-1032. https://doi.org/10.1124/mol.108. 046250

20. Franco-Villanueva A, Fernandez-Lopez E, Gabande-Rodriguez E, Banon-Rodriguez I, Esteban JA, Anton IM, Ledesma MD (2014) WIP modulates dendritic spine actin cytoskeleton by transcriptional control of lipid metabolic enzymes. Hum Mol Genet 23(16):43834395. https://doi.org/10.1093/hmg/ddu155

21. Brann AB, Scott R, Neuberger Y, Abulafia D, Boldin S, Fainzilber M, Futerman AH (1999) Ceramide signaling downstream of the p75 neurotrophin receptor mediates the effects of nerve growth factor on outgrowth of cultured hippocampal neurons. The Journal of neuroscience : the official journal of the Society for Neuroscience 19(19):8199-8206

22. Wheeler D, Knapp E, Bandaru VVR, Wang Y, Knorr D, Poirier C, Mattson MP, Geiger JD et al (2009) TNF $\alpha$-induced neutral sphingomyelinase- 2 modulates synaptic plasticity by controlling the membrane insertion of NMDA receptors. J Neurochem 109(5):1237-1249. https://doi.org/10.1111/j.1471-4159.2009. 06038.x

23. Tabatadze N, Savonenko A, Song H, Bandaru VV, Chu M, Haughey NJ (2010) Inhibition of neutral sphingomyelinase-2 perturbs brain sphingolipid balance and spatial memory in mice. J Neurosci Res 88(13):2940-2951. https://doi.org/10.1002/jnr.22438

24. Kim SK, Ahn KH, Ji JE, Choi JM, Jeon HJ, Jung SY, Jung KM, Kim DK (2010) Neutral sphingomyelinase 2 induces dopamine uptake through regulation of intracellular calcium. Cell Signal 22(5):865-870. https://doi.org/10.1016/j.cellsig.2010.01.012

25. Lee JT, Xu J, Lee JM, Ku G, Han X, Yang DI, Chen S, Hsu CY (2004) Amyloid-beta peptide induces oligodendrocyte death by activating the neutral sphingomyelinase-ceramide pathway. J Cell Biol 164(1):123-131. https://doi.org/10.1083/jcb.200307017

26. Ju TC, Chen SD, Liu CC, Yang DI (2005) Protective effects of Snitrosoglutathione against amyloid beta-peptide neurotoxicity. Free Radic Biol Med 38(7):938-949. https://doi.org/10.1016/j. freeradbiomed.2004.12.019

27. Ong WY, Herr DR, Farooqui T, Ling EA, Farooqui AA (2015) Role of sphingomyelinases in neurological disorders. Expert Opin Ther Targets 19(12):1725-1742. https://doi.org/10.1517/14728222. 2015.1071794 
28. Sperker ER, Spence MW (1983) Neutral and acid sphingomyelinases of rat brain: somatotopographical distribution and activity following experimental manipulation of the dopaminergic system in vivo. J Neurochem 40(4):1182-1184

29. Paxinos G, Watson C (1998) The rat brain in stereotaxic coordinates, 4th edn. Academic Press, San Diego

30. Livak KJ, Schmittgen TD (2001) Analysis of relative gene expression data using real-time quantitative PCR and the 2(-Delta Delta C(T)) method. Methods 25(4):402-408. https://doi.org/10.1006/ meth.2001.1262

31. Alshehry ZH, Barlow CK, Weir JM, Zhou Y, McConville MJ, Meikle PJ (2015) An efficient single phase method for the extraction of plasma lipids. Meta 5(2):389-403. https://doi.org/10.3390/ metabo5020389

32. Taruno A, Sun H, Nakajo K, Murakami T, Ohsaki Y, Kido MA, Ono F, Marunaka Y (2017) Post-translational palmitoylation controls the voltage gating and lipid raft association of the CALHM1 channel. J Physiol. https://doi.org/10.1113/JP274164

33. Powell SB, Swerdlow NR, Pitcher LK, Geyer MA (2002) Isolation rearing-induced deficits in prepulse inhibition and locomotor habituation are not potentiated by water deprivation. Physiol Behav 77(1):55-64. https://doi.org/10.1016/S0031-9384(02)00817-X

34. Clarke CJ, Cloessner EA, Roddy PL, Hannun YA (2011) Neutral sphingomyelinase 2 (nSMase2) is the primary neutral sphingomyelinase isoform activated by tumour necrosis factoralpha in MCF-7 cells. The Biochemical journal 435(2):381-390. https://doi.org/10.1042/BJ20101752

35. Orito A, Kumanogoh H, Yasaka K, Sokawa J, Hidaka H, Sokawa Y, Maekawa S (2001) Calcium-dependent association of annexin VI, protein kinase $\mathrm{C}$ alpha, and neurocalcin alpha on the raft fraction derived from the synaptic plasma membrane of rat brain. J Neurosci Res 64(3):235-241. https://doi.org/10.1002/jnr.1071

36. Alvarez-Guaita A, Vila de Muga S, Owen DM, Williamson D, Magenau A, Garcia-Melero A, Reverter M, Hoque M et al (2015) Evidence for annexin A6-dependent plasma membrane remodelling of lipid domains. Br J Pharmacol 172(7):1677-1690. https:// doi.org/10.1111/bph.13022

37. Cornely R, Rentero C, Enrich C, Grewal T, Gaus K (2011) Annexin A6 is an organizer of membrane microdomains to regulate receptor localization and signalling. IUBMB Life 63(11):1009-1017. https://doi.org/10.1002/iub.540

38. Lim YA, Giese M, Shepherd C, Halliday G, Kobayashi M, Takamatsu K, Staufenbiel M, Eckert A et al (2012) Role of hippocalcin in mediating Abeta toxicity. Biochim Biophys Acta 1822(8):1247-1257. https://doi.org/10.1016/j.bbadis.2012.04.007

39. Spence MW, Burgess JK, Sperker ER (1979) Neutral and acid sphingomyelinases: somatotopographical distribution in human brain and distribution in rat organs. A possible relationship with the dopamine system. Brain Res 168(3):543-551

40. Gatt S (1976) Magnesium-dependent sphingomyelinase. Biochem Biophys Res Commun 68(1):235-241

41. Gault CR, Obeid LM, Hannun YA (2010) An overview of sphingolipid metabolism: from synthesis to breakdown. Adv Exp Med Biol 688:1-23

42. Hannun YA, Luberto C, Argraves KM (2001) Enzymes of sphingolipid metabolism: from modular to integrative signaling. Biochemistry 40(16):4893-4903

43. Enrich C, Rentero C, de Muga SV, Reverter M, Mulay V, Wood P, Koese M, Grewal T (2011) Annexin A6-linking $\mathrm{Ca}(2+)$ signaling with cholesterol transport. Biochim Biophys Acta 1813(5):935947. https://doi.org/10.1016/j.bbamcr.2010.09.015
44. Canals D, Perry DM, Jenkins RW, Hannun YA (2011) Drug targeting of sphingolipid metabolism: sphingomyelinases and ceramidases. Br J Pharmacol 163(4):694-712. https://doi.org/10. 1111/j.1476-5381.2011.01279.x

45. Airola MV, Hannun YA (2013) Sphingolipid metabolism and neutral sphingomyelinases. Handb Exp Pharmacol 215:57-76. https:// doi.org/10.1007/978-3-7091-1368-4 3

46. Haughey NJ, Cutler RG, Tamara A, McArthur JC, Vargas DL, Pardo CA, Turchan J, Nath A et al (2004) Perturbation of sphingolipid metabolism and ceramide production in HIV-dementia. Ann Neurol 55(2):257-267. https://doi.org/10.1002/ana.10828

47. Kolmakova A, Kwiterovich P, Virgil D, Alaupovic P, KnightGibson C, Martin SF, Chatterjee S (2004) Apolipoprotein C-I induces apoptosis in human aortic smooth muscle cells via recruiting neutral sphingomyelinase. Arterioscler Thromb Vasc Biol 24(2): 264-269. https://doi.org/10.1161/01.ATV.0000112036.72200.ac

48. Marchesini N, Hannun YA (2004) Acid and neutral sphingomyelinases: roles and mechanisms of regulation. Biochem Cell Biol 82(1):27-44. https://doi.org/10.1139/003-091

49. Smith AR, Visioli F, Frei B, Hagen TM (2006) Age-related changes in endothelial nitric oxide synthase phosphorylation and nitric oxide dependent vasodilation: evidence for a novel mechanism involving sphingomyelinase and ceramide-activated phosphatase 2A. Aging Cell 5(5):391-400. https://doi.org/10.1111/j.1474-9726.2006. 00232.x

50. Seidler RD, Bernard JA, Burutolu TB, Fling BW, Gordon MT, Gwin JT, Kwak Y, Lipps DB (2010) Motor control and aging: links to age-related brain structural, functional, and biochemical effects. Neurosci Biobehav Rev 34(5):721-733. https://doi.org/10.1016/j. neubiorev.2009.10.005

51. Carlezon WA Jr, Thomas MJ (2009) Biological substrates of reward and aversion: a nucleus accumbens activity hypothesis. Neuropharmacology 56(Suppl 1):122-132. https://doi.org/10. 1016/j.neuropharm.2008.06.075

52. Gray EG (1959) Axo-somatic and axo-dendritic synapses of the cerebral cortex: an electron microscope study. J Anat 93:420-433

53. Klemann CJ, Roubos EW (2011) The gray area between synapse structure and function-Gray's synapse types I and II revisited. Synapse 65(11):1222-1230. https://doi.org/10.1002/syn.20962

54. Besshoh S, Bawa D, Teves L, Wallace MC, Gurd JW (2005) Increased phosphorylation and redistribution of NMDA receptors between synaptic lipid rafts and post-synaptic densities following transient global ischemia in the rat brain. J Neurochem 93(1):186194. https://doi.org/10.1111/j.1471-4159.2004.03009.x

55. Hou Q, Huang Y, Amato S, Snyder SH, Huganir RL, Man HY (2008) Regulation of AMPA receptor localization in lipid rafts. Mol Cell Neurosci 38(2):213-223. https://doi.org/10.1016/j.men. 2008.02.010

56. Hering H, Lin CC, Sheng M (2003) Lipid rafts in the maintenance of synapses, dendritic spines, and surface AMPA receptor stability. The Journal of neuroscience : the official journal of the Society for Neuroscience 23(8):3262-3271

57. Sakai K, Akiyama K, Kashihara K, Tsuchida K, Ujike H, Kuroda S, Shohmori T (1997) AMPA receptors modulate dopamine release in the striatum, as measured by brain microdialysis. Neurochem Int 30(3):329-336

58. Wiedholz LM, Owens WA, Horton RE, Feyder M, Karlsson RM, Hefner K, Sprengel R, Celikel T et al (2008) Mice lacking the AMPA GluR1 receptor exhibit striatal hyperdopaminergia and 'schizophrenia-related' behaviors. Mol Psychiatry 13(6):631-640. https://doi.org/10.1038/sj.mp.4002056 